
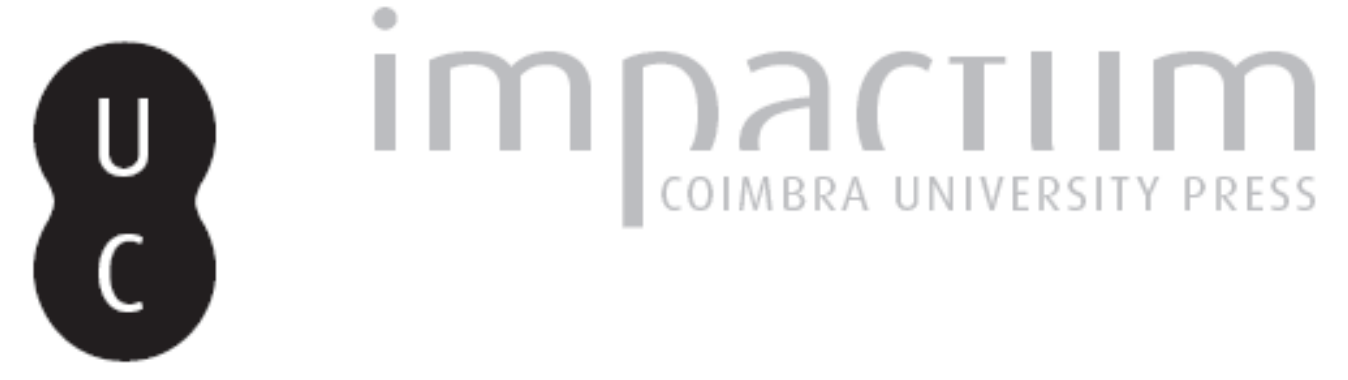

Agravamento da saúde e vulnerabilidades climáticas e socioeconómicas: indivíduos
com AVC, dispneia e asma e dor torácica (Porto, 2005-2008)

Autor(es): $\quad$ Moreira, Maria; Monteiro, Ana

Publicado por: Associação Portuguesa de Riscos, Prevenção e Segurança; Imprensa da Universidade de Coimbra

URL

persistente:

URI:http://hdl.handle.net/10316.2/39727

DOI: DOI:https://doi.org/10.14195/1647-7723_23_3

Accessed : $\quad$ 26-Apr-2023 14:08:26

A navegação consulta e descarregamento dos títulos inseridos nas Bibliotecas Digitais UC Digitalis, UC Pombalina e UC Impactum, pressupõem a aceitação plena e sem reservas dos Termos e Condições de Uso destas Bibliotecas Digitais, disponíveis em https://digitalis.uc.pt/pt-pt/termos.

Conforme exposto nos referidos Termos e Condições de Uso, o descarregamento de títulos de acesso restrito requer uma licença válida de autorização devendo o utilizador aceder ao(s) documento(s) a partir de um endereço de IP da instituição detentora da supramencionada licença.

Ao utilizador é apenas permitido o descarregamento para uso pessoal, pelo que o emprego do(s) título(s) descarregado(s) para outro fim, designadamente comercial, carece de autorização do respetivo autor ou editor da obra.

Na medida em que todas as obras da UC Digitalis se encontram protegidas pelo Código do Direito de Autor e Direitos Conexos e demais legislação aplicável, toda a cópia, parcial ou total, deste documento, nos casos em que é legalmente admitida, deverá conter ou fazer-se acompanhar por este aviso. 


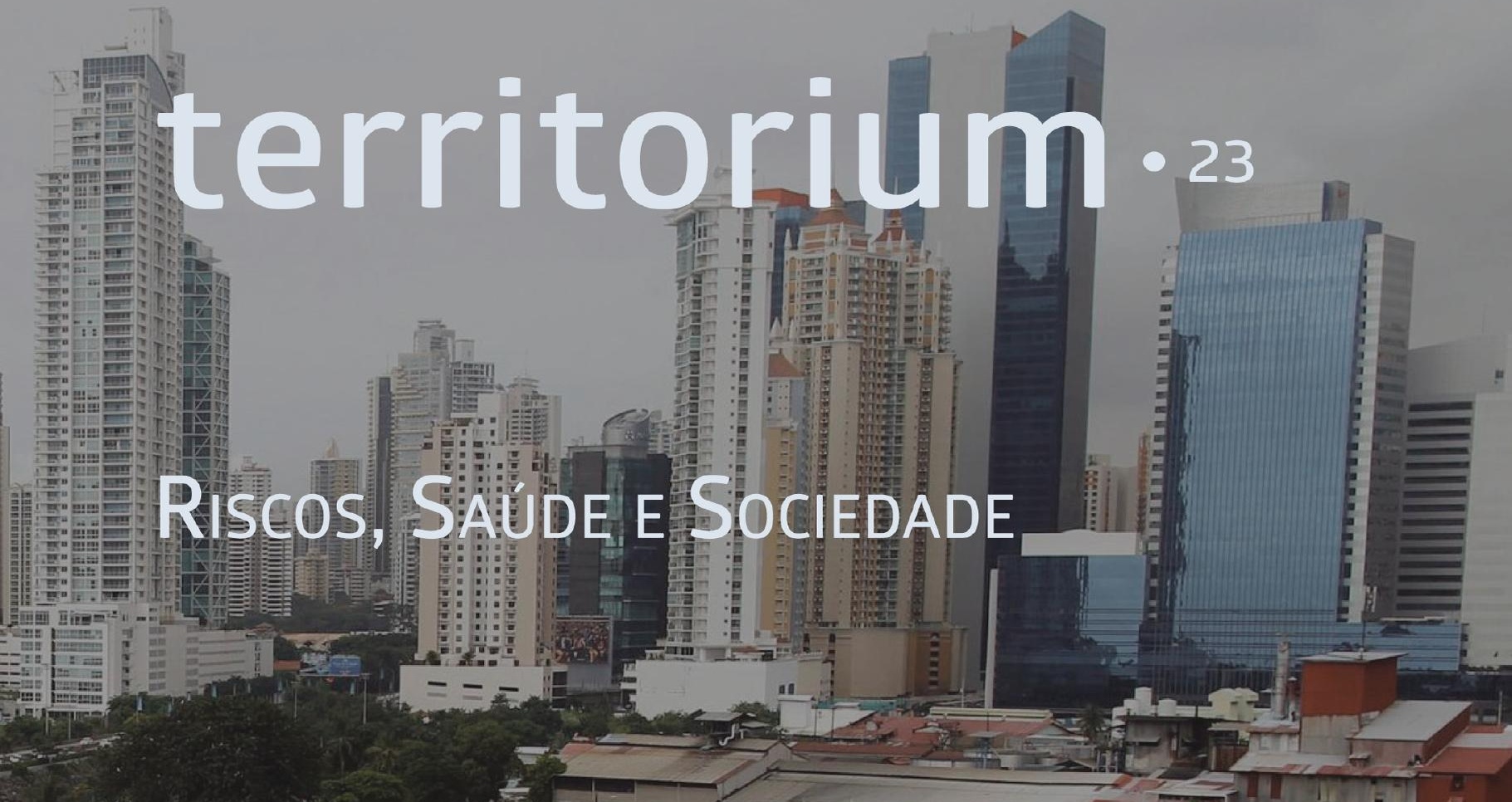

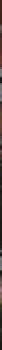

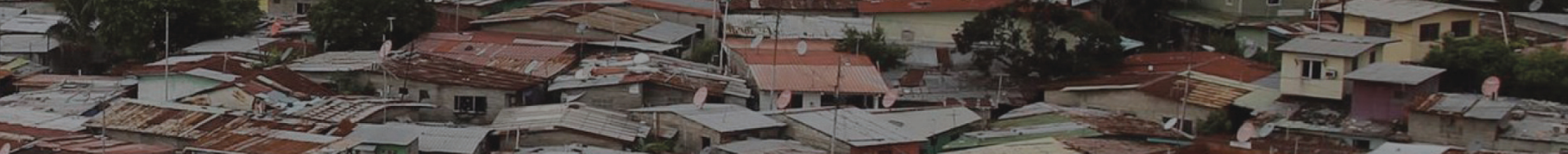

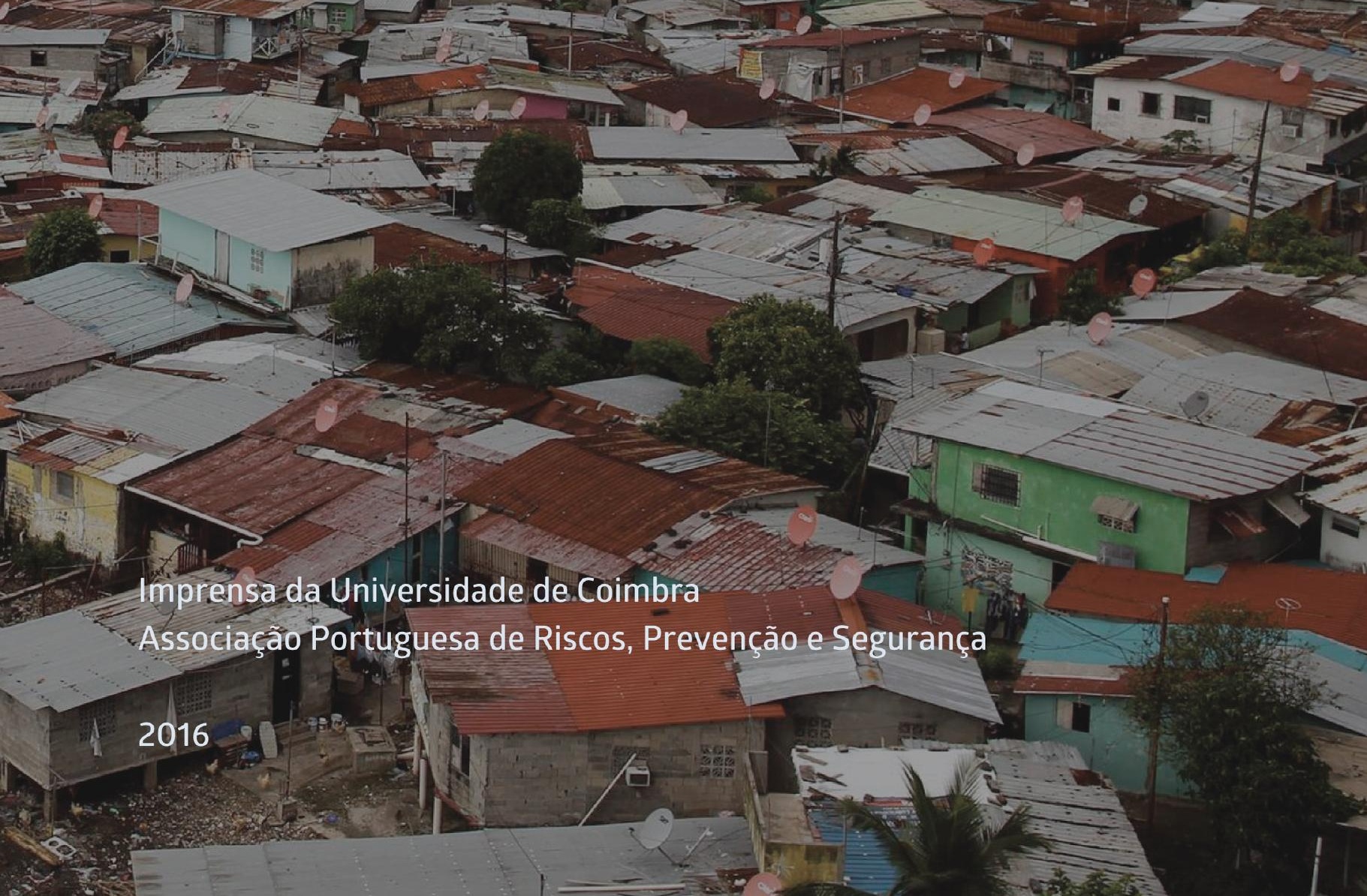




\section{AGRAVAMENTO DA SAÚDE E VULNERABILIDADES CLIMÁTICAS E SOCIOECONÓMICAS: INDIVÍDUOS COM AVC, DISPNEIA E ASMA E DOR TORÁCICA (PORTO, 2005-2008)*}

\section{HEALTH WORSENING AND CLIMATIC AND SOCIOECONOMIC VULNERABILITIES: INDIVIDUALS SUFFERING FROM CEREBROVASCULAR ACCIDENT, DYSPNEA AND ASTHMA AND THORACIC PAIN (PORTO, 2005-2008)}

\section{Maria Moreira \\ Ministério da Educação e Ciência mmoreira11@gmail.com \\ Ana Monteiro}

Departamento de Geografia - UP; ISPUP, Projeto ERA/URBAN/0001/2009; CITTA, Porto. Portugal anamonteirosousa@gmail.com

\section{RESUMO}

Este trabalho de investigação tem como objetivo averiguar as relações existentes entre a saúde (ocorrências na urgência com AVC, Dispneia \& Asma e Dor Torácica) e o contexto socioambiental dos doentes, a partir da análise de múltiplas variáveis, de modo a contribuir para a identificação de fatores que possam ajudar a explicar a distribuição e magnitude do número de ocorrências diárias de urgências e, assim, fornecer informações úteis para a definição de medidas que permitam antecipar e mitigar o problema, minimizando a exposição ao risco de desenvolvimento ou agravamento das doenças mencionadas.

Palavras-chave: Clima, condições socioeconómicas, saúde, morbilidade, vulnerabilidade.

\section{ABSTRACT}

This research work has the goal of ascertaining the existent relationship between health (occurrences in emergency services due to Cerebrovascular Accident, Dyspnea \& Asthma and Thoracic Pain) and the patients' socioenvironmental context, through the analysis of multiple variables, in order to contribute towards identification of factors which may explain the distribution and the magnitude of the number of daily admissions at the emergency services and, therefore, giving useful information towards the definition of measures which allow to anticipate and mitigate the problem, minimizing exposure to the risk of developing or worsening of these diseases.

Keywords: Climate, socioeconomic conditions, health, morbidity, vulnerability.

\section{RESUMEN}

Agravamiento de la salud y vulnerabilidades climáticas y socioeconómicas: individuos con AVC, disnea asociada a asma y dolor torácico (Oporto, 2005-2008) - Este trabajo de investigación tiene como objetivo averiguar las relaciones existentes entre la salud (eventos en la urgencia con AVC, disnea asociada a asma y dolor torácico) y el contexto socio ambiental de los enfermos, a partir del análisis de múltiples variables. Se trata de contribuir a la identificación de factores que puedan ayudar a explicar la distribución y magnitud del número de eventos diarios de urgencias y así, proporcionar informaciones útiles para la definición de medidas que permitan anticipar y mitigar el problema, minimizando la exposición al riesgo de aparición o empeoramiento de estas enfermedades.

Palabras clave: Clima, condiciones socioeconómicas, salud, morbilidad, vulnerabilidad.

\section{RESUMÉ}

L'aggravation de la santé et les vulnérabilités socio-économiques : les individus victimes d'AVC de dyspnée \& asthme et de douleurs thoraciques (Porto, 2005-2008) - Ce travail de recherche a pour but d'étudier les relations entre la santé (occurrences en cas d'urgence avec des patients qui souffrent d'un AVC, dyspnée, asthme et douleurs thoraciques) et le contexte socio-environnemental des malades. C'est une analyse de variables multiples, susceptibles de contribuer à l'identification de facteurs qui puissent aider à expliquer la distribution et l'amplitude de la fréquence d'occurrences d'un jour à l'autre. Cette recherche est à même de fournir aussi des informations utiles pour la définition des mesures qui permettent d'une part d'anticiper et d'atténuer le problème et d'autre part, de minimiser l'exposition au risque de développement ou d'aggravation de ces maladies.

Mots-clé: Climat, conditions socio-économiques, santé, morbidité, vulnérabilité.

* O texto deste artigo foi submetido em 29-11-2015, sujeito a revisão por pares a 24-03-2016 e aceite para publicação em 31-03-2016.

Este artigo é parte integrante da Revista Territorium, $n .{ }^{\circ} 23,2016,{ }^{\circ}$ RIscos, ISSN: 0872-8941. 


\section{Introdução}

As cidades, pela sua importância demográfica, já que albergam a maior parte da população do Globo (UNEP, 2010), são um espaço de análise relevante para uma sociedade que se proponha promover a qualidade de vida das suas populações e constituem-se, por isso, como um objeto de estudo privilegiado no processo de construção do desenvolvimento sustentável. A rápida evolução e progresso tecnológico que a nossa sociedade experienciou nas últimas décadas, produziram transformações profundas no espaço urbano e alteraram a nossa forma de viver e interagir com a cidade, fazendo emergir novas necessidades e novos problemas, alguns dos quais obstam à qualidade de vida da população urbana e legitimam a necessidade de serem considerados nas decisões políticas.

O modo como planearmos o espaço urbano e como definirmos a sua orgânica interna contribui para a construção efetiva de cidades sustentáveis e para a promoção da qualidade de vida da população. Para o efeito, temos de perceber muito bem o metabolismo próprio da cidade, identificando não só os problemas a resolver como também as potencialidades que poderão oferecer. Este processo exige a adopção de uma perspetiva sistémica, dada a complexidade de abordagem e de intervenção no quadro da sustentabilidade urbana, aproveitando todos os contributos das diversas áreas do conhecimento. Neste quadro, a Geografia como ciência integradora "de uma miríade de processos dinâmicos, indispensável tanto para conhecer, explicar e antecipar os processos naturais, como para entender os mecanismos de funcionamento da sociedade, como, ainda, para perceber as formas de relacionamento entre ambos (sociedade e processos naturais), apresenta-se como um excelente instrumento para colaborar na interpretação de fenómenos, que só podem ser percebidos, com abordagens sistémicas efectuadas, simultaneamente, pelas ciências naturais e pelas ciências sociais" (A. Monteiro, 2008).

A resposta ao desafio da promoção da segurança, saúde e bem-estar das pessoas passa pela capacidade dos técnicos e entidades responsáveis anteciparem o risco e pela adopção de medidas que diminuam a exposição ao risco (A. Monteiro, 2008). Mas as respostas do planeamento e ordenamento do território não têm conseguido acompanhar as constantes transformações, que, na maioria das vezes, acabam por ser mais rápidas do que a capacidade de encontrar as respostas e as capacidades de execução adequadas, sucedendo-se constrangimentos vários que comprometem a saúde e o bem-estar das populações.

O princípio da precaução, expresso pela adopção de medidas preventivas adequadas adquire um papel fundamental na prossecução deste propósito. 0 processo conducente à realização de projeções que permitam antecipar o comportamento das pessoas e do território e, assim, diminuir os riscos de perdas e danos, pressupõe a análise das ocorrências registadas no passado, bem como a aferição das respetivas consequências. Torna-se, portanto, necessário conhecer o passado para poder interpretar o presente e antever o futuro. Com este estudo, pretendese dar um contributo para aprofundar/acrescentar conhecimento sobre as relações entre o clima, a saúde e a (in)justiça socioeconómica e ambiental, através da análise dos registos de entrada na urgência com AVC, Dispneia \& Asma e Dor Torácica, no Hospital Geral de Santo António (HGSA) - Porto, num quadro interrelacional com as caraterísticas físicas e humanas da cidade do Porto.

\section{Objetivos da investigação}

Impõe-se, então, a necessidade de perceber como o ordenamento do território poderá contribuir para a promoção da qualidade de vida da população urbana, privilegiando, nesta investigação, a componente da saúde. Por conseguinte, é propósito deste trabalho averiguar as relações existentes entre a saúde e o contexto socioambiental, a partir da análise de variáveis como a idade, o género, a dimensão da família, o rendimento, a literacia, a qualidade da habitação, o sítio e a posição geográfica do local de residência, da distribuição intra-anual das ocorrências na urgência com Acidente Vascular Cerebral (AVC), Dispneia \& Asma e Dor Torácica, no HGSA, da população residente no Porto, no período compreendido entre 1 de Janeiro de 2005 a 31 de Dezembro de 2008, de modo a contribuir para a identificação de fatores que possam ajudar a explicar a distribuição e magnitude do número de ocorrências diárias e, assim, fornecer informações úteis para a definição de um conjunto de medidas que permitam antecipar e mitigar o problema, minimizando a exposição ao risco. Assim, a nossa hipótese de trabalho consiste em avaliar se há alguma relação expressiva entre o agravamento dos sintomas de AVC, Dispneia \& Asma e Dor Torácica e o contexto térmico e/ou o ambiente socioeconómico e ambiental vivenciados. Para o efeito, colocaram-se as seguintes perguntas de investigação:

1. A distribuição das ocorrências das patologias em estudo permite a identificação de algum padrão...

a) ... no que se refere à distribuição por idades e por géneros?

b) ... no que se refere à distribuição espacial?

c) ... no que se refere à distribuição intraanual? 
2. Em caso afirmativo, quais os fatores de risco associados à deterioração da saúde dos residentes portuenses?

3. Existe alguma caraterística do regime térmico que se possa associar à ocorrência de episódios severos em cada uma das patologias?

4. Em caso afirmativo, quais as condições de agravamento?

Os efeitos do clima na saúde: uma relação complexa e pluridimensional

A saúde, como componente essencial do bem-estar humano que é, sempre assumiu destacada importância no contexto dos estudos académicos. A condição de saudável é determinada pela ação e condição física de cada individuo, mas também por fatores que the são alheios e sobre os quais não tem qualquer capacidade de decisão/ controlo. Para R. Bonita et al., (2010), os determinantes de saúde são definidos como fatores sociais, económicos, culturais e ambientais, a maioria dos quais fora do setor da saúde, mas responsáveis pela manutenção da saúde ou instalação da doença no indivíduo.

Nesta investigação iremos centrar a nossa atenção sobretudo nos fatores socioeconómicos e ambientais (fig. 1), particularmente no estudo da relação do elemento climá-

\section{Ordenamento do território}

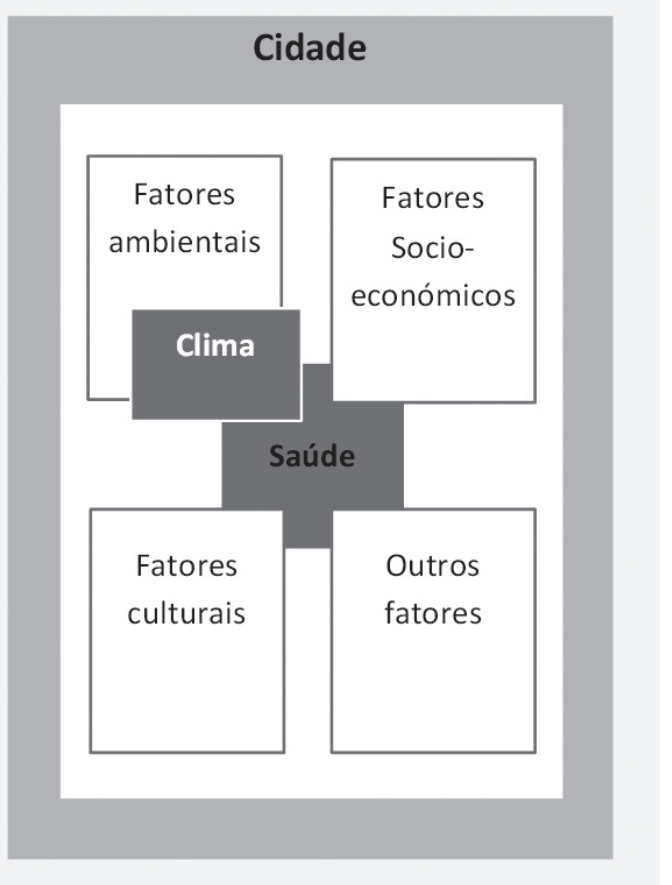

Fig. 1 - Esquema síntese da perspetiva de análise explorada na investigação.

Fig. 1 - Synthesis scheme of the analytical perspective explored in the research. tico temperatura com a afluência ao serviço de urgência, por AVC, Dispneia \& Asma e Dor Torácica. Estas doenças merecem uma atenção redobrada, na medida em que constituem as principais causas de morte, morbilidade e invalidez da população portuguesa. As doenças cardiovasculares, onde se insere o AVC, são a principal causa de mortalidade em Portugal, tal como se verifica em muitos países ocidentais, sendo considerada, no entanto, das mais elevadas da Europa e do Mundo (DGS, 2003).

O clima é um fator determinante para o bem-estar do ser humano, não só porque condiciona o seu conforto mas também porque interfere diretamente com a sua saúde. Os efeitos do clima na saúde têm vido a ser estudados por diversos autores, tendo-se intensificado nas últimas décadas com a ação internacional sobre as evidências das alterações climáticas (WHO, 2009). O IPCC, no seu relatório de 2007 sobre as mudanças do clima (IPPC, 2007), alerta para as consequências para a saúde humana da previsão da ocorrência de fenómenos climáticos extremos mais intensos e frequentes, salientando a maior vulnerabilidade das populações com altas taxas de doença.

Um dos eventos climáticos extremos mais investigados na relação com a mortalidade humana tem sido as ondas de calor. Uma exposição excessiva ao calor constitui um fator de stresse para o organismo, particularmente para o sistema cardiovascular (DGS, 2008 e 2009). Segundo F. Canouï-Poitrine et al. (2006), a onda de calor que afetou a França em Agosto de 2003 foi responsável por quase 15 mil mais mortes, quando comparadas com o mesmo período em anos de referência - 2000, 2001 e 2002, sendo Paris uma das áreas mais severamente afetadas. As caraterísticas da população vitimada por este paroxismo revelam também diferenças comparativamente com as dos anos de referência: são sobretudo idosos, que vivem sozinhos. A. Flynn et al., (2005), estudou também o impacto da onda de calor em Paris em 2003 e concluiu que a população idosa foi mais vulnerável a este evento, salientando que o stresse de calor pode desencadear uma série de complicações na saúde que podem culminar com a morte. A este respeito sugeriu uma série de medidas que devem ser implementadas ao nível das habitações, mas também no que respeita à necessidade de um maior acompanhamento dos idosos, no sentido de minimizar os efeitos na mortalidade. As intervenções, quer no parque habitacional quer nos espaços exteriores, no sentido de minimizar os efeitos para a saúde dos episódios climáticos extremos, designadamente das ondas de calor, foi uma das razões apontadas por L. Kalkstein et al. (2007), para explicar a menor mortalidade da onda de calor de 2003 em Shanghai, comparativamente com a de 1998. Segundo este autor, o forte crescimento na utilização de ar condicionado, entre 1998 e 2003, (de 68,6 para 135,8 condicionadores/ 100 famílias, respetivamente, em 1998 e 2003) e a maior preocupação com o aumento de espaços verdes na construção e modernização urbana 
(a cobertura de área verde urbana aumentou em extensão de $19,1 \%$ para $35,2 \%$, no mesmo período), ajudam a explicar porque é que apesar dos eventos climáticos extremos terem sido de magnitude muito semelhante, em 2003 a mortalidade foi significativamente mais baixa.

A Organização Mundial de Saúde (OMS) tem também dedicado atenção a esta problemática, designadamente nos eventos internacionais que tem promovido. $\mathrm{Na} 4^{\mathrm{a}}$ Conferência Ministerial Ambiente e Saúde realizada entre 23 a 25 de Junho de 2004, em Budapeste, foram adoptadas recomendações sobre as medidas a desenvolver para prevenir e minimizar os efeitos na saúde de ocorrências climáticas extremas, com vista à redução da morbilidade e mortalidade que lhes estão associadas. Foram, também, as questões relacionadas com a interação entre fatores ambientais e saúde que estiveram na base da organização da Primeira Conferência Interministerial sobre Saúde e Ambiente em África, subordinada ao tema "Segurança da saúde graças a ambientes saudáveis", realizada em Libreville, no Gabão, entre 26 a 29 de Agosto de 2008.

A Conferência foi organizada conjuntamente pela OMS e pelo Programa das Nações Unidas para o Ambiente (UNEP), com o objetivo de promover uma abordagem integrada às políticas ambientais e de saúde e para obter as mudanças institucionais necessárias à redução das ameaças ambientais à saúde.

Inúmeros estudos têm apresentado resultados que sugerem a existência de uma relação direta ou indireta das variáveis ambientais, concretamente o estado de tempo, com a morbilidade e a mortalidade em diversos países do mundo, com contextos climáticos e socioeconómicos muito diversificados. As abordagens sobre esta temática têm sido múltiplas, quer no que se refere às variáveis ambientais estudadas, como a temperatura, a humidade do ar, a velocidade do vento, a concentração de ozono ou a concentração de poluentes, quer no que se refere à caraterística dessa variável, como a intensidade, a duração ou a variação. Alguns autores abordam a relação clima-saúde através da identificação de um limiar de temperatura (extremos climáticos), a partir do qual os efeitos na mortalidade são aumentados (C. Linares et al., 2008; S. Näyhä, 2005; L. Kalkstein et al., 1999; M. Falagas, 2009). É de referir, contudo, que esse limiar varia de região para região, dado que os climas também são muito diferentes ao longo da superfície terrestre. S. Näyhä, (2005), apresenta diferentes limiares de temperatura médias diárias, susceptíveis de causar stresse térmico, para três contextos geográficos: $14^{\circ} \mathrm{C}$ na Finlândia (cita S. Näyhä, 1981), $25^{\circ} \mathrm{C}$ nos países do Mediterrâneo e $32^{\circ} \mathrm{C}$ em Taiwan (cita W. Pan, 1995).

M. Loughnan et al., (2010), estudou a relação das urgências no hospital de Melbourne - Austrália com o comportamento da temperatura, com o objetivo de identificar o limiar de temperatura média a partir do qual a taxa de urgências do enfarte do miocárdio aumenta e verificou que em dias com temperatura média de $30^{\circ} \mathrm{C}$, a média de urgências sofreu um aumento de $10,8 \%$. Concluiu, assim, que a partir de determinados limiares de temperaturas médias a saúde deteriora-se significativamente e a morbilidade aumenta. Reitera, no entanto, a ideia de que esses limiares são relativos e não absolutos, variando em função do contexto climático específico de cada região. Além da referência aos valores extremos, alguns autores apresentam também como fator de risco para a saúde a duração prolongada desses episódios (K. Smoyer, 1998). Outros desenvolvem uma investigação baseada na variação da temperatura e não tanto nos extremos térmicos (I. Kriszbacher et al., 2010; $X$. Cheng et al., 2010). No entanto, as temperaturas extremas têm sido a variável mais recorrente nas investigações realizadas sobre os episódios críticos de mortalidade, em geral, e das doenças cardiovasculares e respiratórias, em particular.

A bibliografia consultada relata que as doenças cardiovasculares e respiratórias são as mais afetadas pelos extremos climáticos. M. Fernández et al., (2014) estudou a relação entre as doenças respiratórias e do aparelho circulatório e os fatores sociais, individuais e ambientais (as ithas de calor e de frio urbano) da população afetada, também na população do Porto, e constata que há correlação entre estes fatores e o agravamento da saúde dos indivíduos. W. Martens, (1998); P. Goodman et al., (2004) e M. Falagas et al., (2009), referem que o tempo frio e o excesso de calor estão associados a maior risco de morte por causas cardiovasculares e infecções respiratórias. F. Esteves, (2010), estudou a relação entre os episódios extremos de temperatura e a variabilidade térmica na época de transição primavera - verão e a ocorrência de enfartes do miocárdio (2000-2007), no concelho do Porto, e confirmou que houve um incremento de enfartes do miocárdio associado às variações térmicas elevadas e amplitudes térmicas excecionais.

Num estudo feito em Inglaterra e País de Gales, no período 1968-1988, foram estabelecidas associações altamente significativas entre a temperatura e a morte por bronquite crónica, pneumonia, doença cardíaca isquémica e cerebrovascular (Langford e Bentham, 1995), citado por W. Martens, (1998). G. Bull e J. Morton, (1975 e 1978), (com dados da Inglaterra e País de Gales para o período de 1963-1966 e de Nova York para o período de 1965-1968), citado por W. Martens, (1998), concluíram que as taxas de mortalidade de enfarte do miocárdio, derrames e pneumonia sobem drasticamente quando a temperatura média desce abaixo de $-10^{\circ} \mathrm{C}$ e sobe acima de $20^{\circ} \mathrm{C}$. Neste estudo não foram encontradas diferenças entre os géneros, mas verificou-se um efeito mais pronunciado nos idosos. P. Goodman et al., (2004), 
encontrou uma associação imediata entre o calor e a mortalidade em Dublin. Cada aumento de $1^{\circ} \mathrm{C}$ na temperatura foi associado com um aumento de $0,4 \%$ na mortalidade total no mesmo dia. Estabeleceu também a associação entre a mortalidade total e o frio. Cada diminuição de $1^{\circ} \mathrm{C}$ na temperatura foi associada a 2,6\% de aumento da mortalidade nos 40 dias seguintes. Estes resultados sugerem que os efeitos do aquecimento surtem efeitos mais imediatos na saúde, enquanto os efeitos do frio são mais intensos, mas manifestam-se passado duas ou três semanas após o período de exposição. Refere, no entanto, que estas associações da temperatura com a mortalidade variam de acordo com a causa de morte. Por exemplo, não encontrou qualquer efeito do calor sobre os eventos cardiovasculares. Pelo contrário, para esta mesma causa de morte, a diminuição da temperatura originou um aumento da mortalidade nas três semanas seguintes. Este autor cita outros estudos feitos sobre a mortalidade cardiovascular, na Holanda (M. Huynen et al., 2001), na Escócia (I. Gemmell et al., 2000) e EUA (A. Braga et al., 2000), que comprovam que os efeitos do calor na mortalidade são imediatos (no próprio dia ou no dia seguinte), enquanto os efeitos do frio persistem por vários dias ou semanas. C. Linares et al., (2008), no estudo que fez sobre Madrid verificou que se regista um aumento da mortalidade quando a temperatura ultrapassa um determinado limiar, sobretudo para as idades superiores a 65 anos. A determinação desse limiar foi feita recorrendo ao percentil 95 da série das temperaturas máximas diárias nos meses de Verão: $36,5^{\circ} \mathrm{C}$ para o caso de Madrid. Os resultados mostraram que, à exceção das idades inferiores a 10 anos, em todas as outras idades quando esta temperatura é ultrapassada produz-se um pico de mortalidade, que pode acontecer com 1 ou 2 dias de desfasamento. No entanto, a magnitude do impacto é variável e aumenta com a idade. Por cada grau acima dos $36,5^{\circ} \mathrm{C}$ o aumento da mortalidade é de 13,1\% para o grupo de 18-44 anos, $11,5 \%$ para o grupo de $45-64$ anos, $18,3 \%$ para o grupo $65-74$ anos e $20,1 \%$ para o grupo com mais de 74 anos.

O desfasamento entre a ocorrência do episódio climático que desencadeia o efeito na saúde e a sua manifestação clínica é também referida em outros estudos e para diferentes patologias (G. Bull e J. Morton, 1975; G. Donaldson et al., 1997; S. Näyhä, 2005; F. Ye et al., 2001; M. Amorim e P. Murara, 2010; M. Amorim et al. 2010).

\section{Metodologia e dados}

O desenvolvimento da presente investigação envolveu um processo metodológico que compreendeu a análise e tratamento dos registos diários das entradas nas urgências, cujo destino da alta foi o internamento com AVC, Dispneia \& Asma e Dor Torácica, ocorridos entre 1 de Janeiro de 2005 e 31 de Dezembro de 2008, no HGSA, que foram previamente extraídos do sistema Alert, analisados e validados pelo Dr. Humberto Machado, diretor do Serviço de Urgência do HGSA.

Foram realizadas duas abordagens distintas aos dados. A primeira refere-se ao tratamento estatístico da informação recolhida, segundo os critérios da idade, género e distribuição espacial cruzando-os com o contexto socioeconómico ao nível da subsecção. $\mathrm{Na}$ segunda, estabeleceu-se a comparação dos dados das patologias com o contexto biogeofísico, particularmente ao nível térmico registado, a partir da aquisição dos registos diários da temperatura na Estação Climatológica de Porto - Serra do Pilar, entre 1 de Janeiro de 2005 e 31 de Dezembro de 2007. A nossa análise incidiu apenas sobre os registos diários das urgências por AVC, Dispneia \& Asma e Dor Torácica no HGSA, relativas à população residente no concelho do Porto, pelo que foi necessário filtrar os dados. Concluído o processo de triagem dos dados, foram apurados para a análise 5103 urgências por AVC, 3285 urgências de Dispneia \& Asma e 1276 urgências de Dor Torácica (TABELA I).

TABELA I - Número de registos na urgência do HGST (2005-07), por patologia, no concelho do Porto.

TABLE I - Number of records in emergency services at HGST (2005-07), according to the disease, at the county of Porto.

\begin{tabular}{|c|c|c|c|c|}
\hline & & AVC & $\begin{array}{l}\text { Dispneia } \\
\text { \& asma }\end{array}$ & $\begin{array}{l}\text { Dor } \\
\text { Torácica }\end{array}$ \\
\hline \multicolumn{2}{|c|}{$\begin{array}{l}\text { Total de registos do } \\
\text { concelho do Porto }\end{array}$} & 6957 & 3680 & 1476 \\
\hline \multicolumn{2}{|c|}{$\begin{array}{l}\text { Registos sem } n .^{\circ} \text { de } \\
\text { processo }\end{array}$} & 1368 & 217 & 122 \\
\hline \multicolumn{2}{|c|}{$\begin{array}{l}\text { Registos com } n .^{\circ} \text { processo } \\
\text { mas sem morada }\end{array}$} & 66 & 29 & 7 \\
\hline \multicolumn{2}{|c|}{$\begin{array}{l}\text { Total de registos com } \\
\text { morada omissa }\end{array}$} & 1434 & 246 & 129 \\
\hline \multicolumn{2}{|c|}{$\begin{array}{l}\text { Registos erradamente inse- } \\
\text { ridos no concelho do Porto }\end{array}$} & 289 & 147 & 71 \\
\hline \multicolumn{2}{|c|}{$\begin{array}{l}\text { Registos com morada } \\
\text { identificada }\end{array}$} & 5234 & 3287 & 1276 \\
\hline \multicolumn{2}{|c|}{ Registos repetidos } & 131 & 2 & 0 \\
\hline \multirow{2}{*}{$\begin{array}{l}\text { Registos } \\
\text { apurados para } \\
\text { análise }\end{array}$} & N. ${ }^{\circ}$ & 5103 & 3285 & 1276 \\
\hline & $(\%)$ & 73.4 & 89,3 & 86,4 \\
\hline
\end{tabular}

\section{Análise dos episódios severos em cada uma das patologias}

Na tentativa de procurar perceber o que poderá estar na origem da ocorrência de episódios mais severos do AVC, Dispneia \& Asma e Dor Torácica, consideramos interessante explorar as condições ambientais, designadamente as caraterísticas térmicas associados aos dias em que se verificou um maior número de registos das entradas na urgência em cada uma das patologias. 
Assim, foi necessário selecionar os dias com maior número de entradas na urgência por AVC, Dispneia \& Asma e Dor Torácica. Para o efeito, contamos as entradas na urgência ocorridas, por patologia, em cada um dos dias da série 2005-2008. Após essa contabilização, calculamos os valores de entradas diárias extremamente elevados (percentil 99), com o intuito de identificar os episódios mais severos (TABELA II).

TABELA II - Percentil 99 do número diário de entradas na urgência, por patologia.

TABLE II - 99 Percentile of the daily number of entries at the emergency services, according to the disease.

\begin{tabular}{|c|c|c|}
\hline AVC & Dispneia \& Asma & Dor Torácica \\
\hline $\begin{array}{c}\text { 9 e } 10 \text { registos } \\
\text { de urgência }\end{array}$ & $\begin{array}{c}\text { 6, } 7 \text { e } 8 \text { registos de } \\
\text { urgência }\end{array}$ & $\begin{array}{c}4 \text { e } 5 \text { registos de } \\
\text { urgência }\end{array}$ \\
\hline
\end{tabular}

Com o propósito de averiguar sobre a (in)existência de relações entre a ocorrência de episódios severos de AVC, Dispneia \& Asma e Dor Torácica e as condições climáticas, comparamos a distribuição da frequência dos registos das três patologias com o ritmo das temperaturas máxima (Tmax) e mínima (Tmin) na estação climatológica de Porto - Serra do Pilar, tendo por referência, respetivamente, os percentis 75 e 25 das normais climatológicas da referida estação, nos meses em que se registaram os episódios mais severos. No entanto, essa análise apenas foi possível nos anos de 2005, 2006 e 2007, uma vez que não dispomos de dados climáticos para o ano de 2008, devido ao encerramento da referida estação.

A exploração dos dados foi orientada no sentido de procurar compreender se há alguma caraterística da temperatura que poderá estar associada aos episódios mais severos de cada uma das patologias. Neste sentido, formulou-se a seguinte questão-problema: "Existe alguma caraterística do regime térmico que se possa associar à ocorrência de episódios severos em cada uma das patologias?" Para tentar dar resposta a esta questão, foram elencadas três outras questões, às quais tentamos dar resposta:

Q1 - É o valor (limiar) da temperatura, por si, que contribui para desencadear a ocorrência de episódios severos?

Q2 - É a variação do valor da temperatura relativamente aos dias anteriores que contribui para agravar as condições de saúde destes indivíduos?

Q3 - Qual o período de desfasamento entre o episódio térmico e a ocorrência de um pico de urgências?

\section{Georreferenciação dos dados por morada}

Os dados sujeitos a análise incluem a morada do doente, uma informação imprescindível para proceder à localização da respetiva residência e identificação, em concreto, do contexto ambiental, social e económico do doente. Contudo, tratando-se de dados sujeitos a regras de ética e sigilo muito rigorosas, tivemos, desde início da nossa investigação, cuidados acrescidos tanto no tratamento como na representação cartográfica da informação.

O processo de localização da residência dos indivíduos foi conseguido através da georreferenciação de moradas, recorrendo ao geocoding (ArCGIS). Este processo permitiu obter duas representações diferentes dos dados: um mapa de pontos, com a localização de todos os registos de entradas na urgência georreferenciados e um mapa de coropletas com a representatividade do número de ocorrências de entrada na urgência relativamente ao total da população residente em cada uma das subsecções.

O processo iniciou-se com a correcção e formatação dos dados fornecidos pelo HGSA - 9665 registos, adequando o campo das moradas às regras analíticas do Geocoding. Como informação base utilizada pelo software, foi utilizada uma shapefile, contendo informação do Tele Atlas, designadamente das ruas e números de polícia da cidade do Porto, fornecida pela Environmental Systems Research Institute (ESRI), no âmbito do protocolo existente com o Departamento de Geografia da Faculdade de Letras da Universidade do Porto (FLUP), procedendose à atualização da shapefile, com a inclusão de novas vias e novos números de polícia.

Seguiu-se a realização do Geocoding automático no ArcGis, cujo resultado dos dados georreferenciados foi de $69,5 \%$ para AVC; $76,3 \%$ para Dispneia \& Asma e $73 \%$ para Dor Torácica (TABELA III). Recorremos à utilização de uma ferramenta disponível no software para proceder ao afastamento dos pontos, $10 \mathrm{~m}$ da via, com o objetivo de os inserir dentro da subsecção estatística. No concelho do Porto, quase a totalidade dos limites das subsecções estatísticas coincidem com as vias. Assim, e uma vez que são precisamente as vias a informação base no processo de geocoding, foi necessário deslocar das vias o resultado - pontos - de forma a podermos usar as ferramentas de agregação: moradas>pontos>subsecção. Atendendo a que não consideramos satisfatória a percentagem de dados georreferenciados automaticamente, exportamos os dados não georreferenciados para o GPSVisualizer, onde se procedeu ao Geocoding desses mesmos dados. o resultado foi importado para o projeto e foi feita a confirmação das entradas ao nível da rua. Procedeu-se à agregação desta informação ao resultado do Geocoding feito no ArcGis, tendo-se conseguindo aumentar a percentagem de dados georreferenciados para $77,1 \%$ no AVC; 79,8\% na Dispneia \& Asma e 78,3\% na Dor Torácica. 
Uma vez que as moradas associadas aos bairros não apresentam um formato compatível com o Geocoding, não foi possível georreferenciá-las automaticamente. Por conseguinte, procedemos à georreferenciação manual no ArcGis, o que aumentou substancialmente a percentagem de dados georreferenciados $(87,5 \%$ para AVC; 90,2\% para Dispneia \& Asma e 90,6\% para Dor Torácica) (TABELa III), alcançando, assim, resultados que consideramos muitos satisfatórios. Considerando que, no caso do AVC, existem 198 moradas impossíveis de georreferenciar (devido à inexistência do número de porta), o processo de georreferenciação para esta patologia traduz uma eficácia de $90,1 \%$.

TABELA III - Síntese do processo de georreferenciação realizado. $T_{A B L E}$ III - Synthesis of georeferencing process.

\begin{tabular}{|c|c|c|c|c|c|c|}
\hline & \multicolumn{2}{|c|}{ AVC } & \multicolumn{2}{|c|}{$\begin{array}{l}\text { Dispneia \& } \\
\text { Asma }\end{array}$} & \multicolumn{2}{|c|}{ Dor Torácica } \\
\hline & $\mathrm{N} .{ }^{\circ}$ & $\%$ & N. ${ }^{\circ}$ & $\%$ & N. ${ }^{\circ}$ & $\%$ \\
\hline $\begin{array}{l}\text { Total dados } \\
\text { iniciais }\end{array}$ & 5103 & 100 & 3285 & 100 & 1276 & 10 \\
\hline $\begin{array}{l}\text { Moradas sem } \\
\mathrm{n} .^{\circ} \text { de porta }\end{array}$ & 198 & 3,9 & 0 & 0 & 0 & 0 \\
\hline SubTotal & 4905 & & 3285 & & 1276 & \\
\hline $\begin{array}{l}\text { Georref. } \\
\text { no ArcGis } \\
\text { (autom.) }\end{array}$ & 3547 & 69,5 & 2505 & 76,3 & 932 & 73,0 \\
\hline $\begin{array}{l}\text { Georref. no } \\
\text { GPSVisualiser }\end{array}$ & 387 & 7,5 & 114 & 3,5 & 68 & 5,3 \\
\hline $\begin{array}{l}\text { Georref. } \\
\text { no ArcGis } \\
\text { (manual) }\end{array}$ & 530 & 10,4 & 347 & 10,6 & 156 & 12,2 \\
\hline $\begin{array}{l}\text { Total de dados } \\
\text { georref. }\end{array}$ & 4464 & 87,5 & 2934 & 90,2 & 1156 & 90,6 \\
\hline
\end{tabular}

Análise das entradas na urgência, do HGSA, com AVC, Dispneia \& asma e Dor torácica

Acidente Vascular Cerebral (AVC)

\section{Distribuição por idades e segundo o género}

Para analisar a distribuição dos registos de entradas na urgência com AVC, por idades, foi calculada a taxa de ocorrência do AVC no total de indivíduos de cada classe etária (fig. 2). Os resultados obtidos indicam, claramente, um aumento da taxa de ocorrência do AVC à medida que aumenta a idade. No entanto, o ritmo a que se processa esse aumento não é constante. É, efetivamente, a partir dos 65 anos que se evidencia um aumento bastante pronunciado da taxa de ocorrência do AVC, atingindo quase $9 \%$ dos indivíduos com 90 ou mais anos. Resultado semelhante ao de M. Giroud e M. Lemesle, (1998), onde se refere que com o aumento da idade aumenta o risco de ocorrência de AVC e que a idade superior a 65 anos marca um aumento exponencial das ocorrências.
A distribuição segundo o género evidencia, em termos gerais, três particularidades distintas: o predomínio do género feminino nas classes mais jovens (15 a 39 anos), um equilíbrio nas classes adultas ( 40 a 59) e o predomínio, evidente, do género masculino nas classes mais idosas (acima dos 60 anos), sendo bastante acentuado a partir dos 75 anos, chegando a ultrapassar os $10 \%$ do total de indivíduos do sexo masculino com 90 ou mais anos.

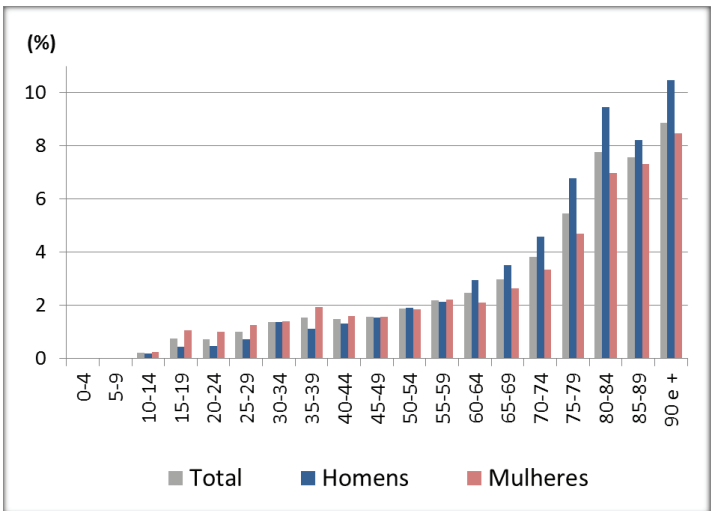

Fig. 2 - Taxa de ocorrência de AVC no total da população, por idades e por género, (HGSA-Porto, 2005-08).

Fig. 2 - Occurrence rate of Cerebrovascular Accident in the total population, by age and gender, (HGSA-Porto, 2005-08).

Seguindo a metodologia atrás explicitada, procurou-se conhecer as caraterísticas da população afetada em episódios severos ou de elevada frequência. Para o efeito, utilizou-se o percentil 99 (P99), que corresponde, no caso do AVC, a 9 ou 10 entradas diárias nas urgências, observados em 21 dias da série 2005-2008. A distribuição da taxa de ocorrência do AVC, por idades, nos episódios mais severos, mantém a tendência observada no total dos registos da série. De destacar, contudo, a forte ocorrência observada a partir dos 90 anos (fig. 3), o que evidencia a maior vulnerabilidade destes indivíduos em episódios severos.

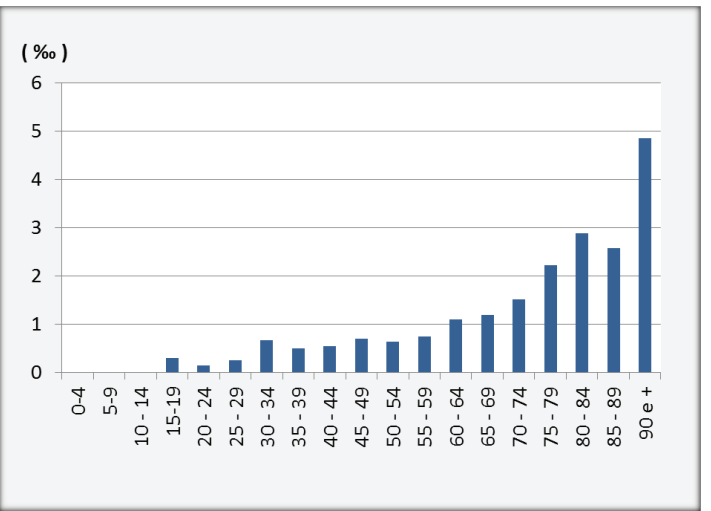

Fig. 3 - Taxa de ocorrência do AVC no total da população, por idades, nos episódios severos, (HGSA-Porto, 2005-08).

Fig. 3 - Occurrence rate of Cerebrovascular Accident in the total population, by age, in severe episodes, (HGSA-Porto, 2005-08). 
Distribuição espacial: ao nível da subsecção

A distribuição absoluta das urgências evidencia uma grande concentração na área central "alargada" da cidade e uma concentração considerável, ainda que menos expressiva, no setor ocidental, com núcleos mais individualizados nos bairros de habitação social e na marginal junto à foz, que se prolonga ao longo da linha de costa. Atendendo a que os valores absolutos não permitem estabelecer comparações entre áreas cuja dimensão demográfica é muito variável, procedemos à relativização dos dados no total de habitantes de cada subsecção (fig. 4). A distribuição dos resultados apresenta grandes desigualdades entre as várias subsecções, oscilando entre 0 e 100\%.

Existem 7 subsecções com taxas iguais ou superiores a $50 \%$, que correspondem a subsecções com poucos habitantes (máximo de 7) e localizam-se principalmente na área central da cidade (freguesias de Miragaia, Cedofeita e Massarelos). Das 1797 subsecções habitadas, 761 (42,3\%) não registam qualquer ocorrência de AVC e localizam-se sobretudo na periferia da cidade.

\section{Distribuição temporal (intra-anual)}

A distribuição do total de registos ao longo do ano não permite aferir qualquer padrão sazonal, uma vez que apresenta distribuições mensais inter-anuais diferentes.
No entanto, no total, verifica-se um ligeiro predomínio em Novembro, Dezembro e Março (meses frios), tal como a bibliografia consultada sugere.

Quando analisada a distribuição dos episódios severos de AVC pelos diferentes meses do ano (fig.5), verificam-se grandes alterações relativamente à distribuição do total de registos da série. Os episódios mais severos de AVC apresentam uma distribuição irregular ao longo do ano. O maior número verificou-se nos meses de Inverno (Dezembro, Janeiro e Fevereiro), seguido dos meses de Verão (Junho, Julho, Agosto e Setembro). Os resultados evidenciam, portanto, uma menor ocorrência nas estações de transição (Primavera e Outono). De salientar o mês de Novembro que, apesar de em termos totais ser o mês com maior número de registos de AVC, não apresenta qualquer ocorrência de episódios severos.

\section{Contexto climático dos episódios mais severos de AVC}

A análise do contexto climático dos episódios mais severos de AVC encontra-se esquematizada na fig. 6 .

Relativamente às três questões apresentadas na metodologia, os resultados indicam que:

Q1 - não há qualquer episódio severo associado a temperaturas máximas consideradas muito elevadas e ocorrem apenas 2 associados a temperaturas mínimas muito baixas. Contudo,

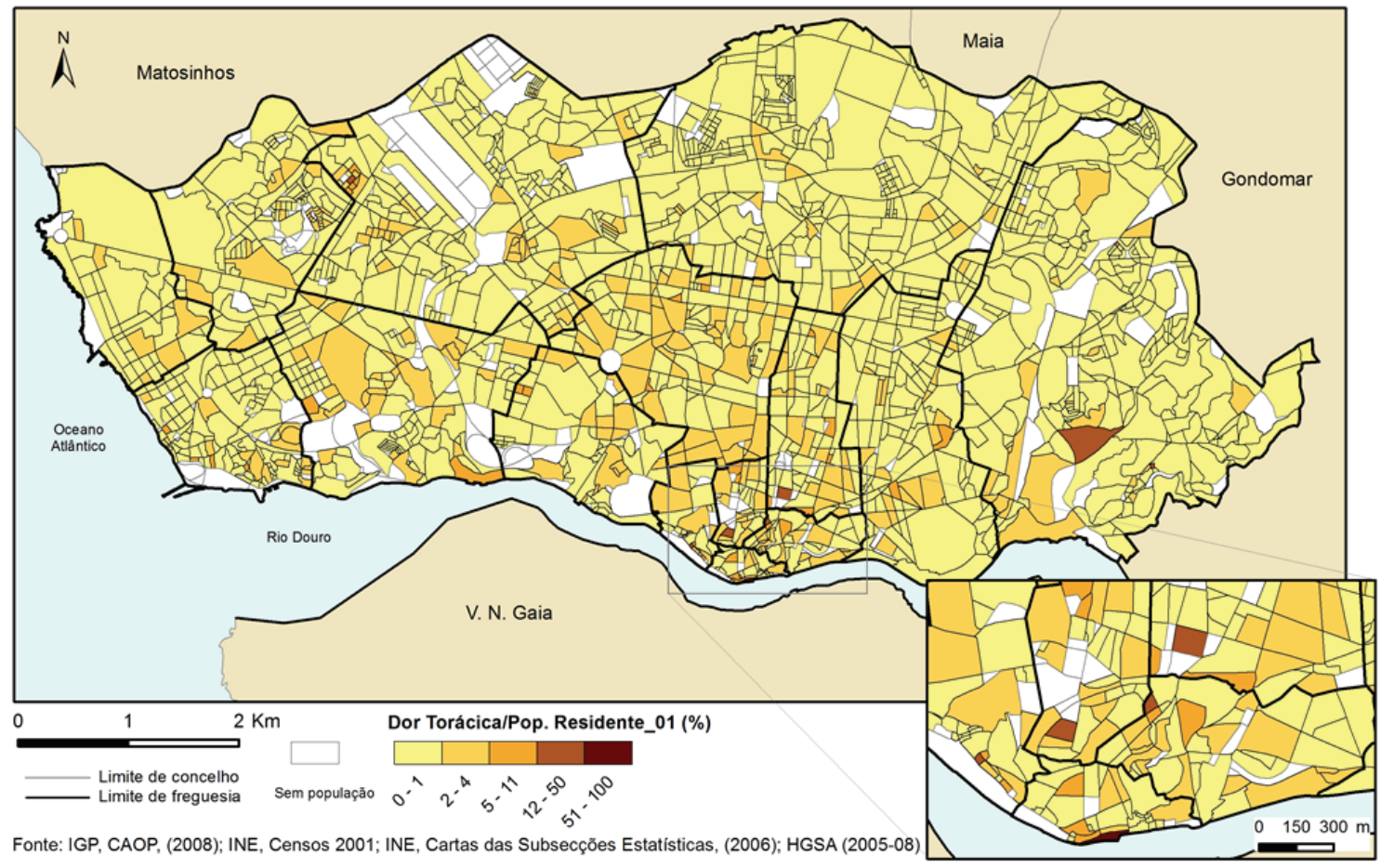

Fig. 4 - Distribuição relativa das urgências com AVC, por subsecção estatística (HGSA-Porto, 2005-08).

Fig. 4 - Relative distribution of occurrences at the emergency services due to Cerebrovascular Accident, by statistical subsection (HGSA-Porto, 2005-08). 


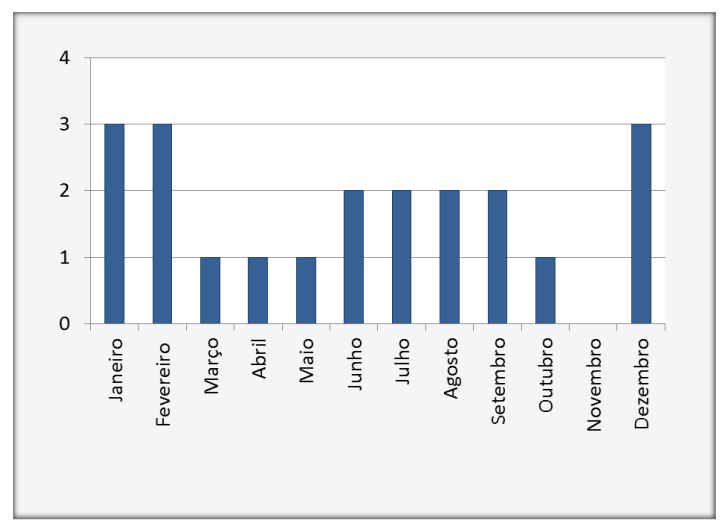

Fig. 5 - Distribuição do n. ${ }^{\circ}$ de episódios severos, por AVC, pelos meses do ano (HGSA-Porto, 2005-08).

Fig. 5 - Distribution of the number of severe episodes for Cerebrovascular Accident, by months (HGSA-Porto, 2005-08).

de salientar que o frio (temperaturas mínimas muito baixas no Inverno [entre 2 e $3^{\circ} \mathrm{C}$ - pouco frequentes para o Porto], ou baixas para a época de Verão [entre 12 e $17^{\circ} \mathrm{C}$ ]) aparece associado a 6 episódios severos. Reitera-se aqui a maior ocorrência do AVC com o tempo frio, apontada na bilbiografia (D. Jakovljevic, 1996; Y. Wang, 2003, G. Donaldson et al., 1997; S. Näyhä, 2005).

Q2 - a variação do valor da Tmax ou Tmin nos dias anteriores à ocorrência dos episódios extremos aparece associada a quase metade (6/13) dos episódios severos. Nesses casos, verificou-se uma considerável variação da temperatura máxima e/ou mínima. A variação está maioritariamente associada à diminuição da temperatura (de 5 a $9^{\circ} \mathrm{C}$ ), embora também se verifiquem situações de aumento. Reitera-se aqui a maior ocorrência do AVC associada ao tempo frio e especialmente à descida da temperatura, referida na bibliografia (D. Jakovljevic, 1996; Y. Wang, 2003, G. Donaldson et al., 1997; S. Näyhä, 2005; C. Guest et al., 1999).

Q3 - o período em que se desencadeia o efeito, corresponde aos 2 ou 3 dias seguintes a descidas ou subidas bruscas da Tmax ou Tmin. S. Näyhä, (2005), aponta também um desfasamento de 3 a 4 dias entre a diminuição da temperatura e o aumento da mortalidade por AVC.

\section{Dispneia \& Asma}

Distribuição por idades e segundo o género

A taxa de ocorrência das urgências com Dispneia \& Asma, por classe etária, apresenta valores quase nulos até aos 40 anos e evidencia um aumento com a idade

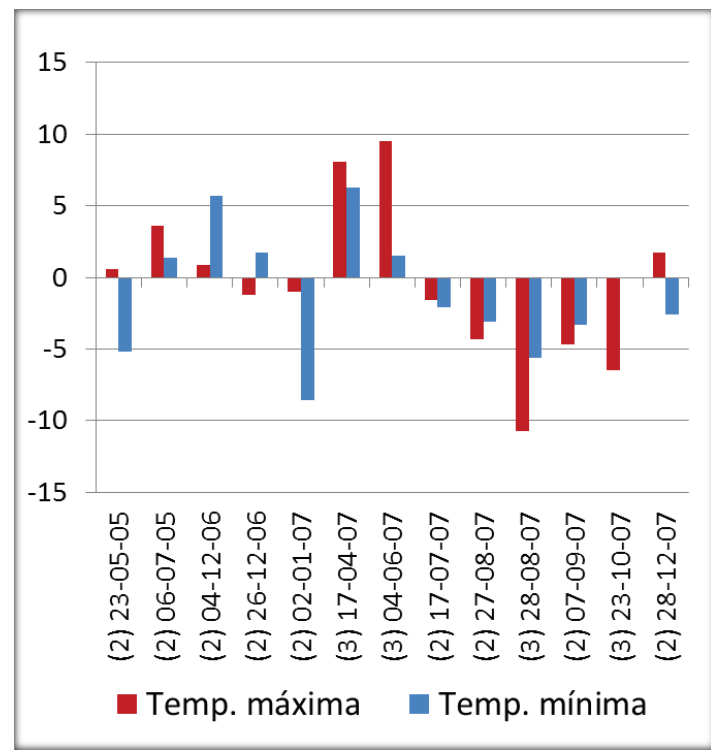

Fig. 6 - Variação das Tmax e Tmin nos dias anteriores aos episódios severos de AVC [no eixo x, (2) corresponde ao $n .{ }^{\circ}$ de dias de desfasamento entre o episódio térmico e o pico de urgências].

Fig. 6 - Variation of Tmax and Tmin in the days before severe episodes of Cerebrovascular Accident [the x axis, (2) corresponds to the number of days lag between the thermal episode and the peak of occurrences at the emergency services].

(fig. 7).Evidencia-se um ritmo de crescimento bastante acentuado a partir dos 70 anos, chegando a atingir os $20 \%$ do total de indivíduos na classe 90 ou mais anos. Em cada uma das classes etárias, o género masculino é o mais afetado, apresentando valores sempre superiores ao género feminino, o que significa que para a mesma idade, os homens apresentam maior ocorrência desta patologia, o que corrobora os resultados apresentados na bibliografia (F. Ye et al., 2001)

No caso da Dispneia \& Asma, o percentil 99 do número de registos diários de urgências, corresponde aos dias com 6, 7 e 8 urgências. Nos episódios mais severos (fig. 8), a distribuição das urgências com Dispneia \& Asma, apresenta essencialmente duas particularidades: um aumento extraordinário da taxa de ocorrência na classe de 90 ou mais anos, comparativamente à classe anterior, e a maior ocorrência na classe compreendida entre os 40 e os 44 anos, ainda que residual, do que na distribuição do total dos registos da série.

\section{Distribuição espacial: ao nível da subsecção}

A distribuição das urgências com Dispneia \& Asma pela cidade mostra grandes desigualdades. 0 maior número de ocorrências (cerca de metade) regista-se no centro da cidade, sendo poucos os casos observados nas freguesias localizadas a Este e Nordeste, como é o caso de Campanhã e Paranhos. Há uma concentração muito 
intensa no núcleo mais antigo da cidade e nos bairros de habitação social do setor Oeste. Os valores relativos da Dispneia \& Asma (fig. 9) exibem também grandes disparidades, oscilando entre 0 e $320 \%$. A ocorrência da Dispneia \& Asma é marcadamente maior na área central da cidade e no alinhamento da avenida da Boavista, destacando-se três subsecções com valores muito elevados, uma na freguesia da Sé, com $100 \%$ e duas na freguesia de São Nicolau, com 200 e 320\%. Estes elevados valores ocorrem devido ao caráter crónico da doença, cujas crises sucessivas podem originar, em contextos demográficos com reduzida população e quando ela é predominantemente idosa (como é o caso), números de

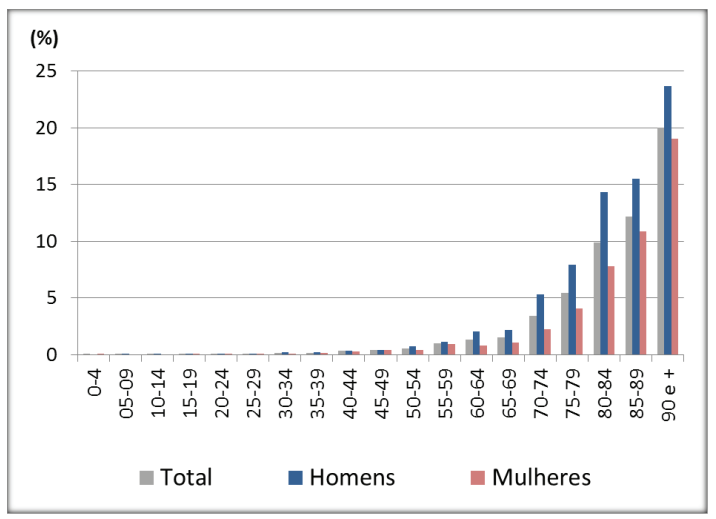

Fig. 7 - Taxa de ocorrência da Dispneia \& Asma no total da população, por idades e género (HGSA-Porto, 2005-08).

Fig. 7 - Occurrence rate of Dyspnea \& Asthma in the total population, by age and gender (HGSA-Porto, 2005-08). urgências muito superiores ao número de habitantes. Existem 43 subsecções $(2,1 \%)$ com uma taxa de ocorrência de Dispneia \& Asma igual ou superior a $10 \%$, que se localizam maioritariamente no centro da cidade.

\section{Distribuição temporal}

A distribuição das urgências com Dispneia \& Asma ao longo do ano permite-nos identificar, nitidamente, uma tendência de distribuição que acompanha as estações do ano. Os registos das urgências de Dispneia \& Asma

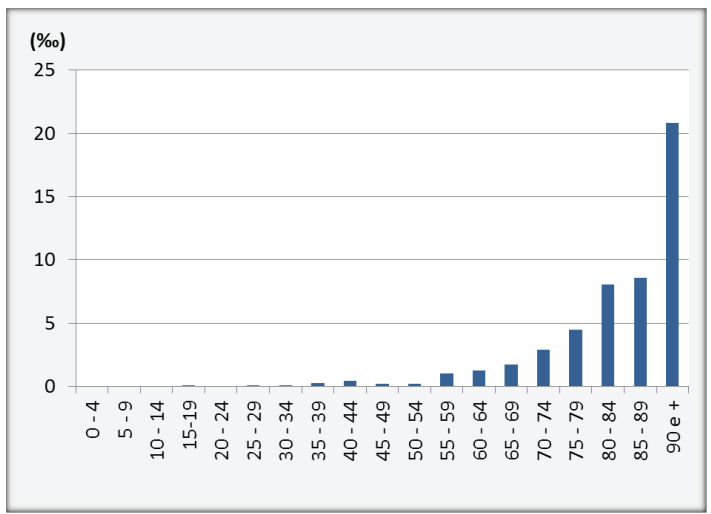

Fig. 8 - Taxa de ocorrência da Dispneia \& Asma no total da população, por idades, nos episódios severos (HGSA-Porto, 2005-08).

Fig. 8 - Occurrence rate of Dyspnea \& Asthma in the total population, by age, in severe episodes (HGSA-Porto, 2005-08). population, by age and gender (HGSA-Porto, 2005-08).

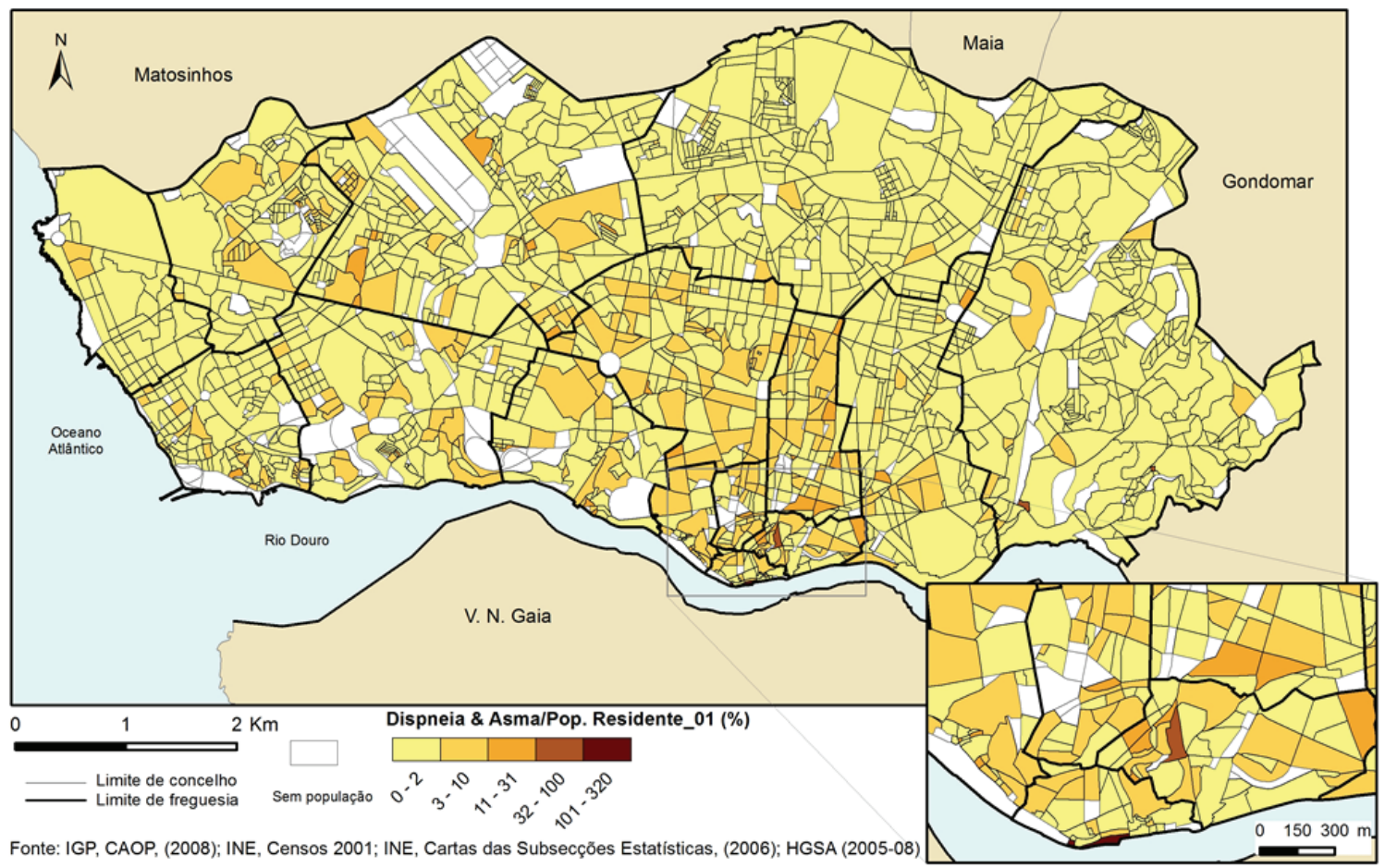

Fig. 9 - Distribuição relativa das urgências com Dispneia \& Asma, por subsecção estatística (HGSA-Porto, 2005-08).

Fig. 9 - Relative distribution of occurrences at the emergency services due to Dyspnea \& Asthma, by statistical subsection (HGSAPorto, 2005-08). 
são mais elevados no Inverno e mais baixos no Verão e, regra geral, aumentam progressivamente do Verão para o Inverno e diminuem progressivamente do Inverno para o Verão. Os resultados sugerem que a estação mais fria é mais favorável à ocorrência desta patologia. Há, contudo, a salientar os valores do mês de Agosto, que interrompem a tendência, sendo mais elevados do que os dos meses de Julho e de Setembro. A maior ocorrência desta patologia nos extremos climáticos está em conformidade com os estudos consultados (A. Monteiro, 1997; A. Monteiro, 1999 e K. Shea et al., 2008). A distribuição dos episódios severos de urgências (6 a 8 registos de urgências) com Dispneia \& Asma pelos meses do ano (fig. 10), reforça a observação atrás referida relativa ao predomínio desta patologia nos meses mais frios. Os meses de Janeiro e Fevereiro destacam-se, contendo 10 ou mais dias com episódios severos.

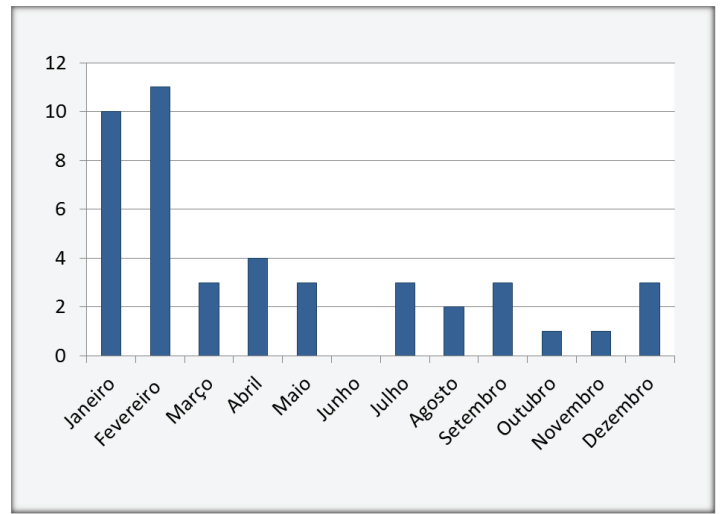

Fig. 10 - Distribuição do $n^{\circ}$ de episódios severos na Dispneia \& Asma, pelos meses do ano (HGSA-Porto, 2005-08).

Fig. 10 - Distribution of the number of severe episodes for Dyspnea \& Asthma, by months (HGSA-Porto, 2005-08).

\section{Contexto climático dos episódios mais severos} de Dispneia \& Asma

A fig. 11 sintetiza a análise da informação sobre o contexto climático dos episódios mais severos de Dispneia \& Asma. Respondendo às questões elencadas inicialmente, constatamos que:

Q1 - no conjunto dos 32 dias analisados, 15 (47\%) apresentam uma Tmin muito baixa, (inferior a $\left.6^{\circ} \mathrm{C}\right)$ e $20(63 \%)$ registam Tmin inferiores a $10^{\circ} \mathrm{C}$, o que aponta para uma possível relação entre contextos climáticos muito frios e a ocorrência de episódios severos de Dispneia \& Asma.

Q2 e Q3 - A variabilidade térmica, nos dois ou três dias anteriores, está também muito presente no enquadramento dos episódios severos. Verificam-se oscilações consideráveis da Tmax e da Tmin. 25 dias (78\%) registam amplitudes térmicas iguais ou superiores a $8^{\circ} \mathrm{C}$, o que aponta para uma relação positiva com os picos de urgências. Poderemos dizer que a ocorrência de episódios severos de Dispneia \& Asma está associada a temperaturas mínimas muito baixas e/ou a oscilações consideráveis da temperatura nos 2 ou 3 dias anteriores. Monteiro et al., (2000), apresenta também, no projeto CLIAS, a grande variabilidade térmica que se prolonga nos 3 dias que precedem as crises de asma, como uma das caraterísticas associadas aos episódios críticos dessa patologia. G. Bull e J. Morton, (1975), refere-se também ao desfasamento de 5 dias entre o dia da descida da temperatura e o dia da ocorrência dos episódios severos nas doenças respiratórias.

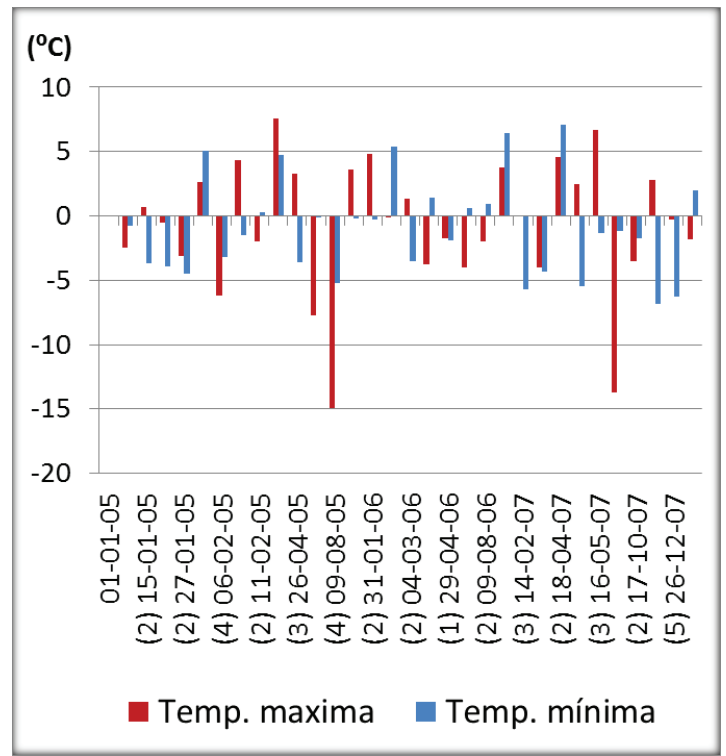

Fig. 11 - Variação das Tmax e Tmin nos dias anteriores aos episódios severos de Dispneia \& Asma [no eixo x, (2) corresponde ao $n .^{\circ}$ de dias de desfasamento entre o episódio térmico e o pico de urgências].

Fig. 11 - Variation of Tmax and Tmin in the days before severe episodes of Dyspnea \& Asthma [the $x$ axis, (2) corresponds to the number of days lag between the thermal episode and the peak of occurrences at the emergency services].

Dor Torácica

\section{Distribuição por idades e segundo o género}

A distribuição da Dor Torácica por classes etárias mostra que até aos 90 anos a taxa de ocorrência aumenta progressivamente, atingindo nessa classe aproximadamente $4,5 \%$ (fig. 12). Nos indivíduos com 90 ou mais anos a taxa de ocorrência diminui, interrompendo a tendência de crescimento até aí verificada. No entanto, o ritmo de crescimento não é regular. Até aos 14 anos a taxa de ocorrência é nula, sendo muito reduzida dos 15 aos 39. É sobretudo a partir dos 40 anos que se 
evidencia o aumento progressivo desta patologia, tendo bastante expressividade a partir dos 70 anos. A maior preponderância no grupo dos idosos está em conformidade com os estudos consultados (W. Martens, 1998; Nakai et al., 1999; G. Bull e J. Morton (1975 e 1978), citado por W. Martens, 1998; Goodman et al., 2005).

Relativamente à distribuição por géneros, verifica-se um extraordinário predomínio dos homens, sendo a taxa de ocorrência no género masculino quase sempre o dobro ou mais da taxa de ocorrência no género feminino. 0 predomínio no género masculino está em concordância com os estudos consultados para as doenças cardiovasculares (P. Koken et al., 2003; Y. Wang et al., 2003; K. Tor et al., 2010), que estão muito associadas à Dor Torácica.

Os resultados obtidos para os episódios mais severos (fig. 13), que correspondem a 4 ou 5 urgências, registados em 26 dias, apresentam algumas diferenças relativamente aos resultados do total da série. A classe etária dos 70 aos 74 anos apresenta muito maior representatividade comparativamente com o total da série. Contrariamente, as classes dos 65 aos 69 e dos 75 aos 79, assumem menor representatividade.

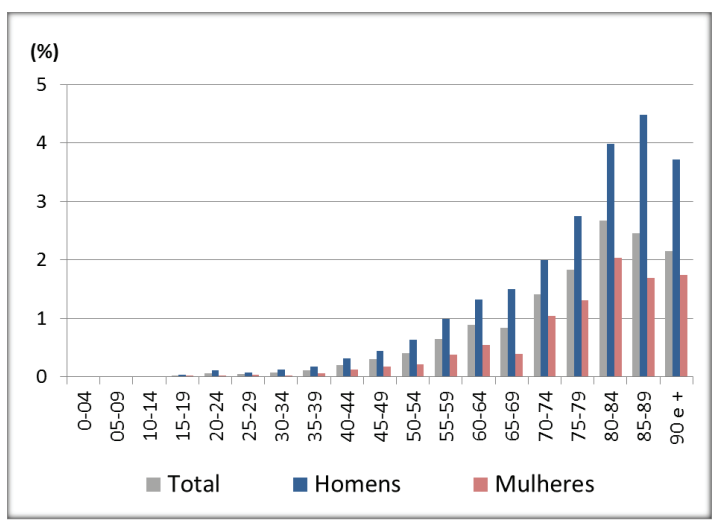

Fig. 12 - Taxa de ocorrência da Dor torácica no total da população, por idades e género (HGSA-Porto, 2005-08).

Fig. 12 - Occurrence rate of Thoracic Pain in the total population, by age and gender (HGSA-Porto, 2005-08).

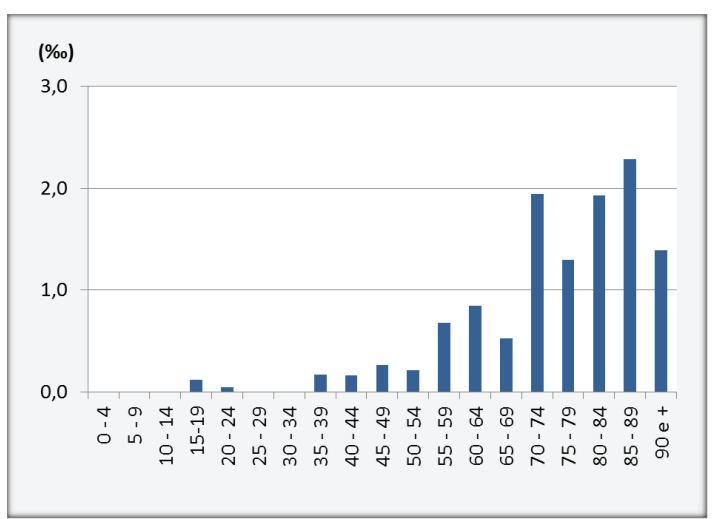

Fig. 13 - Taxa de incidência da Dor Torácica no total da população, por idades, nos episódios severos (HGSA-Porto, 2005-08).

Fig. 13 - Incidence rate of Thoracic Pain in the total population, by age, in severe episodes (HGSA-Porto, 2005-08).
Distribuição espacial: ao nível da subsecção

Verifica-se que há uma maior concentração no centro da cidade, seguido do setor ocidental, principalmente nos bairros de habitação social, onde o número de casos também é significativo, contrariamente aos setores Oriental e Norte. A área limítrofe entre as freguesias de São Nicolau, Sé, Vitória e Miragaia e os bairros de habitação social Pinheiro Torres, Pasteleira, Mouteira, Bessa Leite, Campinas, Aldoar, Francos, Fonte da Moura e Ramalde apresentam a maior concentração de urgências com Dor Torácica.

Em termos relativos (fig. 14), constata-se que há uma maior ocorrência da Dor Torácica também no centro da cidade e no setor ocidental, com maior expressividade na área que corresponde ao centro histórico da cidade e aos bairros anteriormente referidos. 0 maior valor é de 100\% e ocorre numa subsecção da freguesia de São Nicolau, seguido de $50 \%$ em Santo Ildefonso. Seguidamente encontram-se cinco subsecções com valores entre os 12 e $50 \%$, que se localizam nas freguesias de Miragaia, Vitória, Sé, Ramalde e Campanhã.

\section{Distribuição temporal}

A distribuição dos registos das urgências com Dor Torácica ao longo do ano, apesar das diferenças inter-anuais aponta para a existência de uma relação com o regime térmico anual. Os valores mais elevados registam-se no Inverno e os valores mais baixos registam-se no Verão e, regra geral, há um aumento do número de urgências do Verão para o Inverno e vice-versa. Como foi referido na introdução, a associação entre elevada morbilidade e mortalidade e o tempo frio foi apresentada para as doenças cardiovasculares (F.Gonçalves et al., 2007; X. Cheng et al., 2010; G. Donaldson et al., 1997; W. Martens, 1998; M. Medina-Ramón, J. Schwartz, 2007 e M. Fernández et al., 2014), para o enfarte do miocárdio (X. Cheng et al., 2010) e para a morte súbita (X. Cheng et al., 2010 e K. Tör et al., 2010).

Quando analisada a distribuição dos episódios mais severos de Dor Torácica pelos meses do ano (fig. 15), verifica-se que não há qualquer episódio severo em dois dos meses mais quentes do ano (Junho e Julho) e que o maior número de episódios severos (5 dias) ocorreu em Janeiro e Dezembro.

Contexto climático dos episódios mais severos de Dor Torácica

A análise aos resultados permitiu chegar às seguintes conclusões:

Q1 - Os resultados sugerem que as temperaturas mínimas muito baixas poderão estar associadas à ocorrência de episódios severos de Dor Torácica. Dos 25 dias analisados, 9 (36\%) apresentaram temperaturas muito baixas (entre $0^{\circ}$ e $\left.6^{\circ} \mathrm{C}\right), 12(48 \%)$ apresentam 


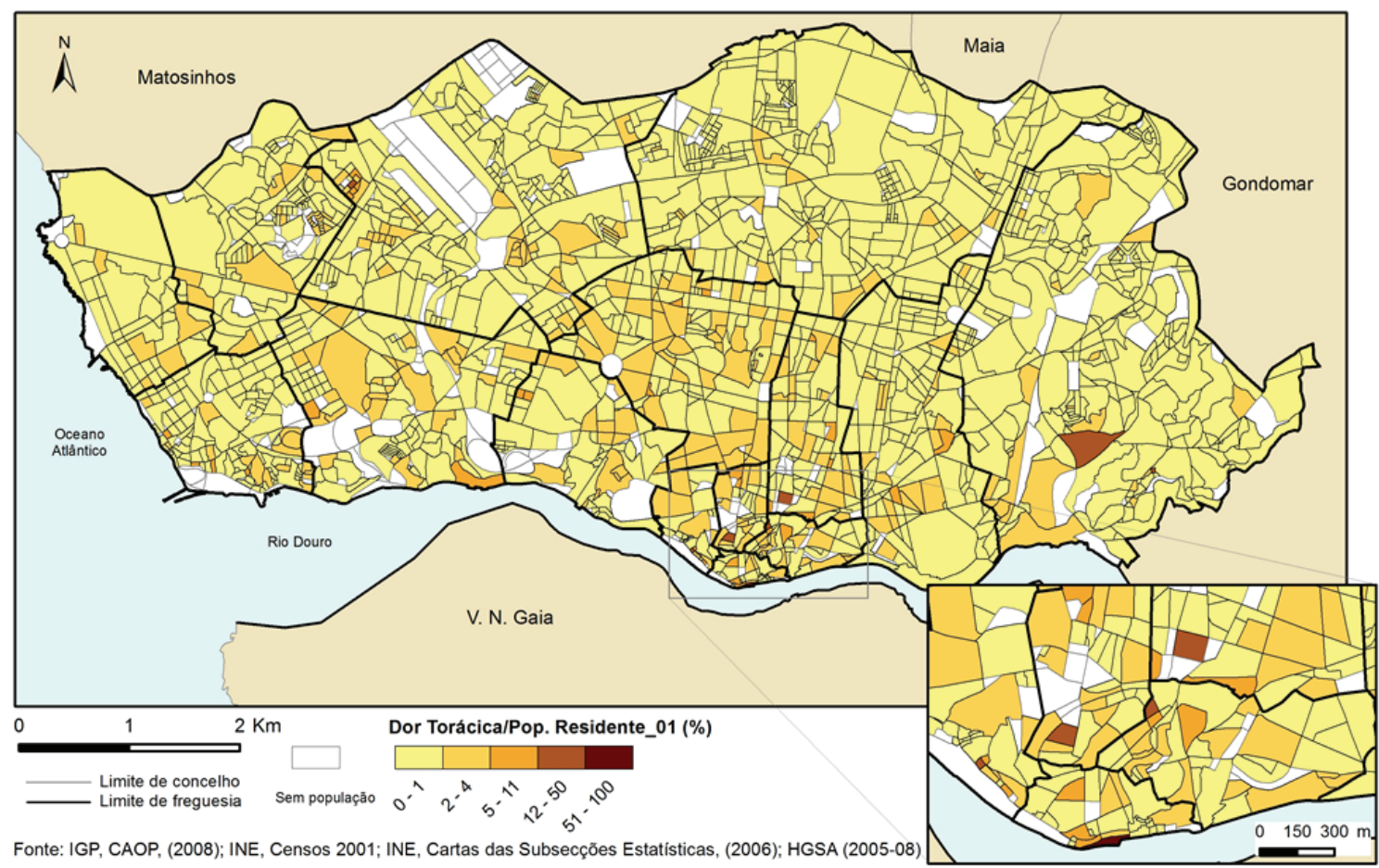

Fig. 14 - Distribuição relativa das urgências com Dor Torácica, por subsecção estatística (HGSA-Porto, 2005-08).

Fig. 14 - Relative distribution of occurrences at the emergency services due to Thoracic Pain, by statistical subsection (HGSA-Porto, 2005-08).

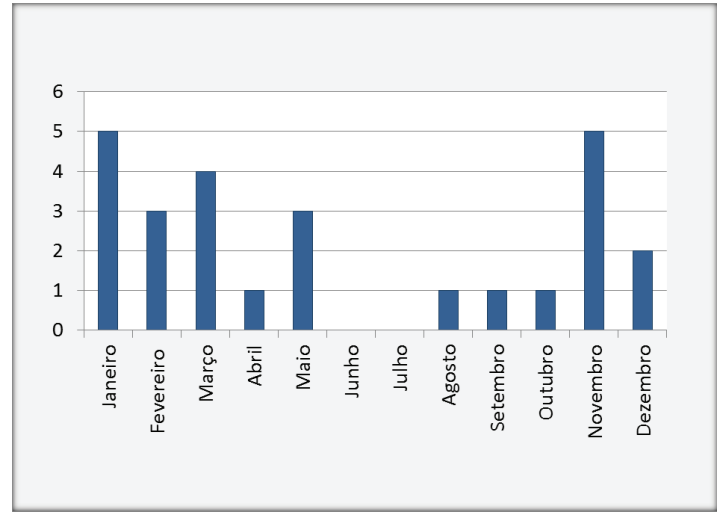

Fig. 15 - Distribuição do $n^{\circ}$ de episódios severos na Dor Torácica, pelos meses do ano (HGSA-Porto, 2005-08).

Fig. 15 - Distribution of the number of severe episodes for Thoracic Pain, by months (HGSA-Porto, 2005-08).

temperaturas inferiores a $10^{\circ} \mathrm{C}$ e $16(64 \%)$ registam temperaturas inferiores a $12^{\circ} \mathrm{C}$.

Q2 - A variabilidade térmica (fig. 16) é uma caraterística que também está associada à ocorrência de episódios severos, sobretudo da Tmin, onde as variações são mais expressivas. Note-se que a variabilidade térmica (amplitude térmica) no mesmo dia apresenta valores muito significativos, com cerca de 14 dias (56\%) com amplitudes térmicas iguais ou superiores a $8^{\circ} \mathrm{C}$.

Q3 - O desfasamento entre o evento térmico e o pico de urgências com Dor Torácica é o mais reduzido das três patologias analisadas, sendo de 1 ou 2 dias. Os resultados sugerem, assim, que os efeitos na morbilidade por Dor Torácica são mais imediatos, ocorrendo, muitas vezes, no dia seguinte ao evento térmico.

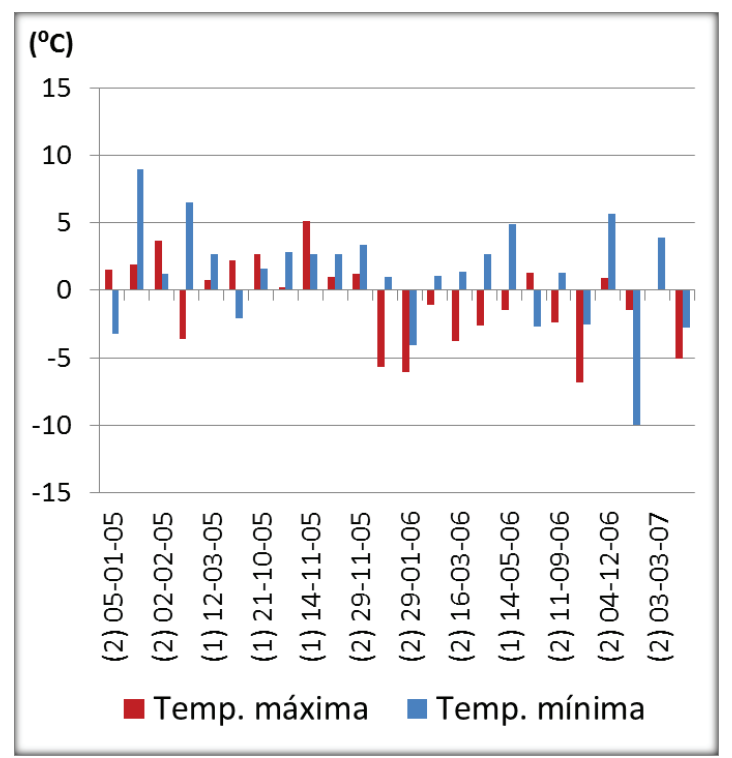

Fig. 16 - Variação das Tmax e Tmin nos dias anteriores aos episódios severos de Dor Torácica [no eixo x, (2) corresponde ao n. ${ }^{\circ}$ de dias de desfasamento entre o episódio térmico e o pico de urgências].

Fig. 16 - Variation of Tmax and Tmin in the days before severe episodes of Thoracic Pain [the $x$ axis, (2) corresponds to the number of days lag between the thermal episode and the peak of occurrences at the emergency services]. 
Comparação dos resultados dos internamentos por AVC, Dispneia \& Asma e Dor Torácica com os fatores socioambientais, à subsecção.

Sendo um dos objetivos deste trabalho averiguar as relações existentes entre o contexto socioambiental e o agravamento do estado de saúde da população residente no Porto, a partir da análise das entradas nos serviços de urgência cujo destino final de alta foi o internamento com diagnóstico de AVC, Dispneia \& Asma e Dor Torácica no HGSA, procuramos avaliar se, de facto, existiam evidências expressivas entre estas variáveis, calculando o coeficiente de correlação entre as séries de registos das três patologias e os indicadores socioambientais de cada indivíduo. No caso do AVC não existem correlações significativas exceto, no P99, com a densidade populacional $(-0,46)$. Encontramos correlações significativas para a Dispneia \& Asma, sobretudo no P99, com as famílias clássicas de 1 e 2 pessoas $(0,59)$, as famílias clássicas de 2 e 3 elementos $(-0,50)$, a altitude média $(-0,54)$ e o declive $(0,67)$. Para a Dor Torácica, no P95 e P99, evidencia-se a correlação sobretudo com a taxa de desemprego $(0,52$ e 0,76 , respetivamente).
A comparação entre as ocorrências de cada uma das três patologias e o contexto socioeconómico de cada indivíduo, elaborada ao nível da subsecção, utilizando sempre o Percentil 95, permitiu-nos identificar que as áreas mais vulneráveis do ponto de vista das caraterísticas socioeconómicas são também aquelas em que a frequência de ocorrência do agravamento do estado de saúde foi maior. A análise comparativa efetuada às subsecções que registaram maior frequência de entradas na urgência, com qualquer uma das três patologias, permitiu-nos delinear algumas caraterísticas do "perfil típico" do contexto biogeofísico e socioeconómico gerador de agravamento da saúde dos portuenses (TABELA IV).

Os fatores de risco mais influentes no agravamento da saúde dos portuenses e a vulnerabilidade à ocorrência de agravamento de AVC, Dispneia \& Asma e Dor torácica.

Partindo das caraterísticas do "perfil típico" do contexto biogeofísico e socioeconómico gerador de agravamento da saúde dos portuenses, identificadas no capítulo anterior, selecionamos aquelas que se

TABELA IV - "Perfil típico” das subsecções com maior ocorrência de AVC, Dispneia \& Asma e Dor Torácica.

TABLE IV - "Typical profile" for the subsections with higher occurrence of Cerebrovascular Accident, Dyspnea \& Asthma and Thoracic Pain.

\begin{tabular}{|c|c|c|c|}
\hline & \multicolumn{3}{|c|}{ Perfil típico das subsecções com maior taxa de ocorrência } \\
\hline & AVC & Dispneia \& Asma & Dor Torácica \\
\hline Índice de envelhecimento & \multicolumn{3}{|l|}{ Elevado $(\geq 200 \%)$} \\
\hline Densidade Populacional & \multicolumn{3}{|l|}{ Elevada ( $\geq 5000 \mathrm{Hab} . / \mathrm{Km}^{2}$ ) } \\
\hline Educação & \multicolumn{3}{|l|}{ Baixo nível educacional } \\
\hline Taxa de desemprego & \multicolumn{3}{|l|}{ Elevada ( $\geq 10 \%)$} \\
\hline Dimensão das famílias & \multicolumn{3}{|l|}{ Reduzida ( 1 ou 2 pessoas) } \\
\hline Caraterísticas dos edifícios & \multicolumn{3}{|l|}{$\begin{array}{l}\text { Edifícios baixos ( } 1 \text { a } 4 \text { pisos) } \\
\text { Edifícios antigos (anteriores a 1961) }\end{array}$} \\
\hline Relevo & $\begin{array}{l}\text { Altitude baixa }(<100 \mathrm{~m}) \\
\text { Declive baixo }(<10 \%) \\
\text { Exposição a Sul e a Este }\end{array}$ & & \\
\hline Espaços verdes & \multicolumn{3}{|l|}{ Reduzidos $\left(<1000 \mathrm{~m}^{2}\right)$} \\
\hline $\begin{array}{l}\text { Distância aos grandes } \\
\text { reservatórios de água }\end{array}$ & $\begin{array}{l}\text { Próximo do rio }(<1000 \mathrm{~m}) \\
\text { Afastado do mar }(\geq 4000 \mathrm{~m})\end{array}$ & $\begin{array}{l}\text { Próximo do rio } \\
<1000 \mathrm{~m})\end{array}$ & $\begin{array}{l}\text { Próximo do rio } \\
(<1000 \mathrm{~m}) \\
\text { Afastado do mar } \\
(\geq 4000 \mathrm{~m})\end{array}$ \\
\hline
\end{tabular}


apresentam como as mais influentes na definição desse mesmo perfil para construir um primeiro esboço do que pode vir a ser a carta de vulnerabilidades para a ocorrência de agravamento de AVC, Dispneia \& Asma e Dor Torácica. Considerando que não se evidenciaram grandes diferenças entre as três patologias, no que se refere aos fatores que podem contribuir para 0 seu agravamento, optamos por utilizar as mesmas variáveis para todas as patologias, procedendo, assim, à construção de uma única carta de vulnerabilidades.

Assim, as variáveis utilizadas para a definição da vulnerabilidade dos indivíduos, face às três doenças, foram o índice de envelhecimento em 2001, os edifícios construídos antes de 1961, as famílias com 1 ou 2 pessoas em 2001 e a área de espaços verdes $\left(\mathrm{m}^{2}\right)$. Para definir os níveis de vulnerabilidade à ocorrência de agravamento de AVC, Dispneia \& Asma e Dor Torácica, dividimos cada um dos indicadores em cinco classes, utilizando o método de classificação das quebras naturais (TABELA V).

A ponderação conjunta dos fatores atrás referidos permitiu a elaboração do esboço da carta de vulnerabilidades, onde se verifica que as subsecções com vulnerabilidade alta ou muito alta correspondem, sobretudo, à área central (baixa) da cidade, ao setor oriental e a bairros de habitação social (fig. 17).

Para a validação do esboço da carta de vulnerabilidades realizamos um exercício de comparação, por patologia, entre o número de subsecções com elevada taxa de ocorrências de urgências (P90) e o número de subsecções com vulnerabilidade muito alta (P90), no sentido de identificar a correspondência entre estes dois indicadores (TABELA VI). Essa comparação mostra

TABELA V - Ponderação dada a cada variável usada na construção do esboço da carta de vulnerabilidades.

TABLE $V$ - Weighing given to each variable used in the construction of the outline for the vulnerabilities' map.

\begin{tabular}{|c|c|c|c|c|c|}
\hline Vulnerabilidade & $\begin{array}{l}\text { Índice de Env. em } \\
2001\end{array}$ & $\begin{array}{l}\text { Edif. Const. antes de } \\
1961\end{array}$ & $\begin{array}{l}\text { Famí } \\
\text { pesso }\end{array}$ & em 2001 & $\begin{array}{l}\text { Área de espaços } \\
\text { verdes }\left(\mathrm{m}^{2}\right)\end{array}$ \\
\hline Muito baixa & $0,0-111,1$ & $0,0-16,7$ & 0,0 & 16,7 & $206337,2-436416,8$ \\
\hline Baixa & $111,2-293,3$ & $16,8-41,5$ & 16,8 & 41,9 & $68405,9-206337,1$ \\
\hline Moderada & $293,4-550,0$ & $45,2-67,9$ & 42,0 & 57,6 & $28761,6-68405,8$ \\
\hline Alta & $550,1-1150,0$ & $68,0-87,5$ & 57,7 & 76,5 & $7869,1-28761,5$ \\
\hline Muito alta & $1150,1-2500$ & $87,6-100$ & 76,6 & 100 & - 7869,0 \\
\hline
\end{tabular}

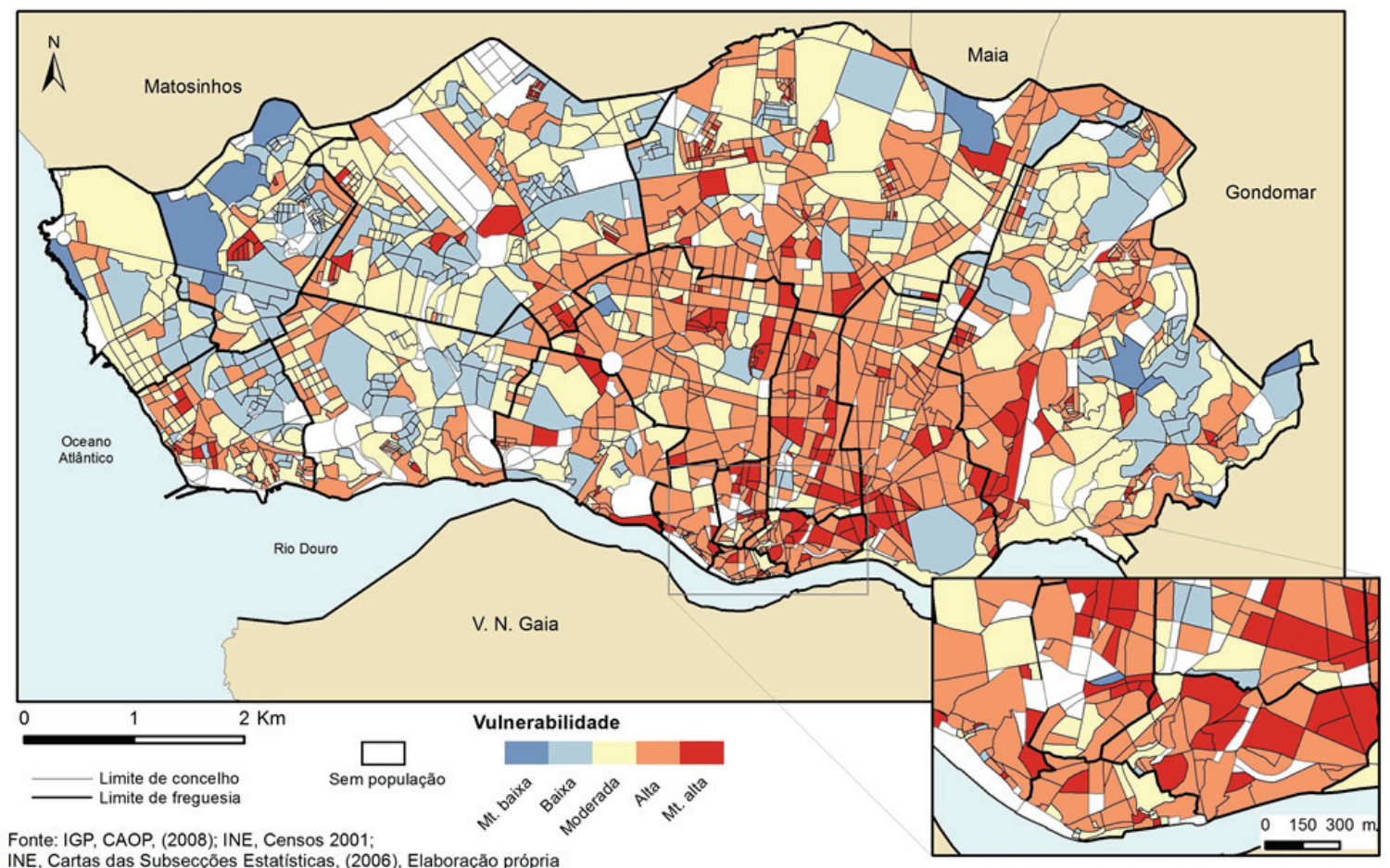

INE, Cartas das Subsecçס̋es Estatisticas, (2006), Elaboraçăo própria

Fig. 17 - Esboço da carta de vulnerabilidade à ocorrência de agravamento de AVC, Dispneia \& Asma e Dor Torácica.

Fig. 17 - Chart outline of the vulnerability to the occurrence of worsening of Cerebrovascular Accident, Dyspnea \& Asthma and Thoracic Pain. 
que a percentagem de subsecções com elevada taxa de ocorrência de urgências (P90) identificadas com elevada vulnerabilidade (P90) é de $29 \%$ para o AVC, $100 \%$ para a Dispneia \& Asma e $96 \%$ para a Dor Torácica. Estes resultados sugerem que os fatores usados na definição da vulnerabilidade (anteriormente expostos) traduzem muito bem a distribuição das ocorrências de episódios de urgência com Dispneia \& Asma e com Dor Torácica e não tanto com AVC.

\section{Discussão dos resultados}

Ao realizar este percurso de investigação confirmamos, por exemplo, que o conjunto de fatores que podem conduzir ao agravamento da saúde da população é muito vasto e bastante complexo, e que, em contextos urbanos, como no caso da cidade do Porto, essa complexidade é ainda substantivamente amplificada tanto pela panóplia de condições sociais, económicas e ambientais (naturais e artificiais), como pela diversidade de padrões de qualidade de vida e bem-estar. A extensão da área de influência do HGSA, que esperávamos que fosse muito mais circunscrita ao centro da cidade do Porto, tendo em conta a sua localização e a existência de mais 3 outros hospitais a NW, NE e a $S$, surpreendeu-nos e autoriza-nos a apreciar os resultados obtidos como representativos da cidade.

Os resultados evidenciam que, de um modo geral, a morbilidade em qualquer uma das patologias estudadas se relaciona diretamente com a da idade dos indivíduos, particularmente a partir dos 65 anos. No entanto, os mesmos resultados sugerem que essa relação é mais evidente no caso da Dispneia \& Asma, onde o aumento das taxas de incidência com a idade dos indivíduos com mais de 65 anos é muito superior.
Pareceu-nos também possível estabelecer, no caso concreto do Porto, uma matriz socioambiental da subsecção que pode ser indutora de maior vulnerabilidade dos indivíduos face ao agravamento da sua saúde e causadora de idas à urgência com diagnósticos de AVC, Dispneia \& Asma e Dor Torácica graves que obrigaram ao seu internamento. Este "perfil típico" pode, grosso modo, ser caraterizado por subsecções com: i) índice de envelhecimento superior a $200 \%$; ii) densidade populacional superior a $5000 \mathrm{hab} / \mathrm{km}^{2}$; iii) população analfabeta ou com o $1 .^{\circ}$ ciclo mais do que $20 \%$; iv) famílias de 1 ou 2 pessoas superiores a 60\%; v) taxa de desemprego acima de 10\%; vi) edifícios anteriores a 1961 acima de $50 \%$; vii) área verde inferior a $1000 \mathrm{~m}^{2}$, etc.

Estes nichos socioeconómicos, indiciadores de privação e de injustiça ambiental e sócio económica, parecem reagir com enorme dificuldade aos episódios térmicos extremos, sobretudo quando se tratam de temperaturas mínimas muito baixas, assim como evidenciam uma frágil adaptação em momentos de grande amplitude térmica diária e de variabilidade térmica considerável nos 2 a 3 dias anteriores aos picos de entrada na urgência, no caso do AVC e Dispneia \& Asma e nos 1 ou 2 dias anteriores, no caso da Dor Torácica.

Os resultados sugerem, assim, que os efeitos dos episódios térmicos extremos ou de grande variabilidade na morbilidade expressam-se a ritmos diferentes em cada uma das patologias, sendo mais imediatos na Dor Torácica do que nas outras patologias, manifestando-se, em muitos casos, no dia seguinte ao evento térmico. Parece-nos, também, que os contextos térmicos extremos geradores de maior vulnerabilidade ao agravamento da saúde, motivada pelas patologias em análise, estão associados ao frio e não tanto ao calor.

TABELA VI - comparação entre as subsecções com elevadas taxas de ocorrências de urgências e as subsecções com vulnerabilidade muito alta.

$T_{A B L E} \mathrm{VI}$ - Comparison between subsections with high rates of occurrences at the emergency services and the subsections with very high vulnerability.

\begin{tabular}{|c|c|c|c|c|c|c|}
\hline & \multicolumn{2}{|c|}{ AVC } & \multicolumn{2}{|c|}{$\begin{array}{l}\text { Dispneia \& } \\
\text { Asma }\end{array}$} & \multicolumn{2}{|c|}{ Dor Torácica } \\
\hline & $\mathrm{N}^{\circ}$ & $\%$ & $\mathrm{~N}^{\circ}$ & $\%$ & $\mathrm{~N}^{\circ}$ & $\%$ \\
\hline $\mathrm{N}^{\circ}$ de subsecções $\mathrm{c} /$ elevada taxa de ocorrências de urgências (P90) & 209 & 10 & 73 & 3,5 & 74 & 3,6 \\
\hline $\mathrm{N}^{\circ}$ de subsecções c/ vulnerabilidade Mt. Alta (P90) & 61 & 3,1 & 73 & 3,5 & 71 & 3,4 \\
\hline $\begin{array}{l}\text { \% de subsecções com elevada taxa de ocorrência de urgências (P90) } \\
\text { identificadas com elevada vulnerabilidade (P90) }\end{array}$ & \multicolumn{2}{|c|}{$29 \%$} & \multicolumn{2}{|c|}{$100 \%$} & \multicolumn{2}{|c|}{$96 \%$} \\
\hline
\end{tabular}




\section{Conclusão}

Concluímos que os indivíduos com mais de 65 anos são sempre, em qualquer das três patologias, os mais vulneráveis. Contudo, durante os "episódios severos" (aqueles em que coincidiram no serviço de urgência um maior número de casos), há uma expressividade relevante de adultos jovens tanto na Dispneia \& Asma como na Dor Torácica. 0 género masculino revelou-se sempre muito mais vulnerável do que o género feminino em qualquer das três patologias. Todavia, no grupo de indivíduos com menos de 59 anos, a maior frequência de AVC foi de indivíduos do género feminino.

No caso do Porto, testemunhamos cartograficamente a existência de uma grande diversidade no que respeita aos hábitos de vida, ao grau de educação formal, à profissão, ao rendimento, à dieta, ao conforto do alojamento, à acessibilidade a áreas verdes e de lazer é enorme, que, de acordo, com a bibliografia consultada, corporizará comportamentos muito diferenciados do risco de agravamento de AVC, Dispneia \& Asma e Dor Torácica, por exemplo, em momentos climaticamente excecionais como os que já constatamos no Porto e que se adivinham que venham a ser cada vez mais recorrentes.

Os resultados alcançados responderam, na maioria dos casos, às questões inicialmente formuladas, sugerindo que existe o que designamos de "perfil típico" de contexto geográfico - biogeofísico e sócioeconómico facilitador do agravamento da sáude dos indivíduos que inclui fatores como: i) a idade; ii) o género; iii) o grau de educação formal; iv) o isolamento; v) a qualidade do alojamento; vi) a qualidade do espaço público envolvente, etc.

Por tudo isto, pensamos que a antecipação do risco de agravamento da saúde dos portuenses que utilizam os Serviços de Urgência do HGSA com diagnósticos de AVC, Dispneia \& Asma e Dor Torácica exige uma atenção muito especial nos momentos de temperatura mínima excepcionalmente baixa, de grande amplitude térmica diária e/ou de grande variabilidade térmica. Todavia, os resultados preliminares alcançados neste trabalho experimental permitem-nos afirmar que as medidas mitigadoras devem, no caso do Porto, ser muito diferenciadas tanto quanto à difusão dos alertas, como à linguagem utilizada e mesmo no que diz respeito aos meios de divulgação escolhidos para disseminar o aconselhamento das medidas de prevenção e mitigação dos danos.

O esboço cartográfico preliminar das vulnerabilidades a partir dos registos diários do HGSA (2005-2007/2008) muito motivado pela oportunidade que o Diretor dos Serviços de Urgência do HGSA, Dr. Humberto Machado, nos deu de ter como matéria-prima de trabalho a distribuição espacial dos dados georreferenciados por morada, permitiu-nos precisamente tornar evidente a necessidade de melhoria na eficácia da utilização do conhecimento científico para minimizar uma boa parte das consequências provocadas por estas patologias nos momentos do ano em que são mais prováveis.

\section{Agradecimentos}

Ao Dr. Humberto Machado, diretor do serviço de urgências do HGSA, pela colaboração no fornecimento da informação relativa aos registos diários das entradas nas urgências, cujo destino da alta foi o internamento com AVC, Dispneia \& Asma e Dor Torácica e ao Filipe Esteves, mestre em SIGOT, pela ajuda na georreferenciação dos dados.

À Fundação para a Ciência e para a Tecnologia (FCT) que financiou a investigação, ao abrigo do programa Compete - Programa Operacional Fatores de Competitividade, no âmbito do projeto ERA NET URBAN/0001/2009.

\section{Bibliografia}

Amorim, M., Murara, P. \& Coelho, M. (2010). Análise da influência meteorológica nas internações por doenças cardiovasculares. Caderno Prudentino de Geografia, v. 32. 2010, pp. 53-65.

Bonita, R., Beaglehole, R. \& Kjellström, T. (2010). Basic

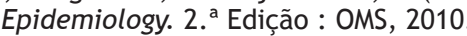

Braga, A. Zanobetti, A. Schwartz, J. (2000). Do respiratory epidemics confound the association between air pollution and daily deaths? Eur Respir J 16(4). 2000, pp. 723-728.

Bull, G, Morton, J. (1975). Relationships of temperature with death rates from all causes and from certain respiratory and arteriosclerotic diseases in different age groups. Age Ageing 1975, 4. 1975, pp. 232-246.

Bull, G. M. and Morton, J. (1978). Environment, temperature and death rates. Age and Ageing 7. 1978, p. 210224.

Bull, G., Morton, J. (1975). Relationships of temperature with death rates from all causes and from certain respiratory and arteriosclerotic diseases in different age groups. Age and Ageing 4. 1975, pp. 232-246.

Canouï-Poitrine, F., Cadot, E. \& Spira. A., (2006). Excess deaths during the August 2003 heat wave in Paris, France. Rev Epidemiol Sante Publique, 54 . 2006, pp. 127-135.

Cheng, X. \& Su, H. (2010). Effects of climatic temperature stresse on cardiovascular diseases. European Journal of Internal Medicine 21. 2010, pp. 164-167.

Curson, P. (1998). Climate and chronic respiratory disease in Sydney - The case of asthma. Climatic Change 25. 1993, pp. 405-420.

DIRECÇÃO GERAL DE SAÚdE (2008). Plano de Contingência para Ondas de Calor. Lisboa.

DIRECÇÃO GERAL DE SAÚdE (2003). Programa Nacional de Prevenção e Controlo das Doenças Cardiovasculares. Lisboa. 
Donaldson, G., Keatinge, W. (1997). Early increases in ischaemic heart disease mortality dissociated from later charges associated with respiratory mortality after cold weather in south east England. Journal of Epidemiology and Community Health, 51. 1997, pp. 643-648.

Esteves, F. (2010). O contributo dos SIG para compreender a relação entre os episódios extremos de temperatura e de variabilidade térmica na época de transição Primavera Verão e a ocorrência de enfartes do miocárdio no concelho do Porto. Porto (Dissertação de Mestrado em SIG). FLUP, Porto, 156pp.

Falagas, M., Karageorgopoulos, D., Moraitis, L., Vouloumanou, E., Roussos, N., Peppas, G. \& Rafailidis, P. (2009). Seasonality of mortality: the September phenomenon in Mediterranean countries. CMAJ, 181 (8). 13 de October de 2009, pp. 484-486.

Fernández Moreno, M., Monteiro, A., Carvalho, V., Gonçalves, G. (2014). True - Ecocentric territory risk units: circulatory and respiratory diseases agravation in Porto. Territorium, n. ${ }^{\circ}$ 21, Coimbra. 2014, pp 157-168. Disponível em: http://www.uc.pt/fluc/nicif/riscos/Documentacao/ Territorium/T21_artg/T21_artg13.pdf.

Flynn, A., Mcgreevy, C. \& Mulkerrin, E. (2005). Why do older patients die in a heatwave? Q J Med 98. 2005, pp. 227-229.

Gemmell, I., McLoone, P., Boddy, F., Dickinson, G. \& Watt, G. (2000). Seasonal variation in mortality in Scotland. Int J Epidemiol 29. 2000, pp. 274-279.

Giroud, M., \& Lemesle, M. (1998). Stroke registries. Cerebrovascular disease: pathophysiology, diagnosis, and management. Blackwell Science Dumas, 2. 1998, pp. 892 - 900.

Gonçalves, F., Braun, S., Dias, P., Sharovsky, R. (2007). Influences of the weather and air pollutants on cardiovascular disease in the metropolitan area of São Paulo. Environmental Research 104. 2007, pp. 275-281.

Goodman, P., Dockery, D., Clancy, L. (2004). CauseSpecific Mortality and the Extended Effects of Particulate Pollution and Temperature Exposure. Environmental Health Perspectives, Volume 112, number 2 . February de 2004, pp. 179-185.

Guest, C., Kalkstein, L., Willson, K., Woodward, A., Hennessy, K. (1999). Climate and mortality in Australia: retrospective study, 1979-1999, and preditecd impacts in five major cities in 2030. Climate Research, Vol. 13. 7 de September de 1999, pp. 1-15.

Huynen, M., Martens, P., Schram, D., Weijenberg, M \&, Kunst, A. (2001). The impact of heat waves and cold spells on mortality rates in the Dutch population. Environ Health Perspect 109. 2001, pp. 463-470.

Jakovljevic, D., Salomaa, V., Sivenius, J., Tamminen, M., Sarti, C., Salmi, K., Kaarsalo, E., Narva, V., Immonen-Räihä, P., Torppa, J., Tuomilehto, J. (1996). Seasonal variation in the occurrence of stroke in a Finnish adult population. The FINMONICA Stroke Register. Finnish Monitoring Trends and Determinants in Cardiovascular Disease. Stroke. 1996;27, pp. 1774-1779.

Kalkstein, L. Chestnut, L., Breffle, W., Smith, J., \& (1998). Analysis of diferences in hotweatherrelated mortality across 44 U.S. Metropolitan areas. Enviromental Science \& Policy,1. 1998, pp. 59-70.
Kalkstein, L., Tan, J., Zheng, Y., Song, G., Kalkstein, A., Tang, X. (2007). Heat wave impacts on mortality in Shanghai, 1998 and 2003. J Biometeorol, 51. 2007, pp. 193-200.

Koken, P., Piver, W., Ye, F., Elixhauser, A., Olsen, L., \&Portier, C. (2003). Temperature, Air Pollution, and Hospitalization for Cardiovascular Diseases among Elderly People in Denver. Environmental Health Perspectives, Volume 111, Number 10. August de 2003, pp. 1312-1317.

Kriszbacher, I., Bódis, J., Koppán, A., Boncz, I., \& Koppán, M. (2010). The effect of climate on heart attack mortality. International Journal of Cardiology 139. 2010, pp. 92-104.

Linares, C., Díaz, J. (2008). Temperaturas extremadamente elevadas y su impacto sobre la mortalidad diaria según diferentes grupos de edad. Gac Sanit 22(2). 2008, pp. 115-9.

Loughnan, M., Nicholls, N., Tapper, N. (2010). When the heat is on: Threshold temperatures for AMI admissions to hospital in Melbourne Australia. Applied Geography 30. 2010, pp. 63-69.

Martens, W. (1998). Climate change, thermal stresse and mortality changes. Soe. Sci. Med. Vol. 46, No. 3. 1998, pp. 331-344.

Medina-Ramón, M., Schwartz, J. (2007). Temperature, temperature extremes, and mortality: a study of acclimatisation and effect modification in 50 US cities. Occup Environ Med. 64 (12). December de 2007, pp. 827-833.

Monteiro, A., Balkestahl L., Góis J., Taesler R. (2008). Os efeitos da intensificação dos processos de urbanização no balanço energético local: estudo de caso no pólo da Asprela. Maputo: 2008. $5^{\circ}$ Congresso Luso-Moçambicano de Engenharia.

Monteiro, A., Madureira, H. (2000). Exemplos de agravamento de algumas patologias do foro respiratório, relacionáveis com as modificações introduzidas pela urbanização portuense na conjuntura climática e na composição química da atmosfera. Porto: FLUP, 2000.

Monteiro, A. (1997). O Ambiente (Urbano): um instrumento de concretização de penas vs um Ecossistema cujas vulnerabilidades urge conhecer. Territorium, $\mathrm{n}^{\circ} 4$, Coimbra. 1997, pp. 11-20. Disponível em: http:// www.uc.pt/fluc/nicif/riscos/Documentacao/ Territorium/T04_artg/T04_Artg02.pdf.

Monteiro, A. (2008). Desenvolvimento, Sustentabilidade ou a busca por um melhor índice de felicidade bruta - o contributo da climatologia urbana. Encontro Internacional Geografia: tradições e perspetivas - homenagem ao centenário de nascimento de Pierre. 2008, S. Paulo.

Murara, P., \& Amorim, M. (2010). Clima e saúde: variações atmosféricas e óbitos por doenças circulatórias. Revista Brasileira de Climatologia, V. 6. 2010, pp. 79-92.

Nakai, S., Itoh, T. \& Morimoto, T. (1999). Deaths from heat-stroke in Japan: 1968-1994. Int $J$ Biometeorol 43. 1999, pp. 124-127.

Näyhä, S. (2005). Environmental temperature and mortality. International Journal of Circumpolar Health 64. 2005, pp. 451-458.

Pan, W., Li, L., Tsai, M. (1995). Temperature extremes and mortality from coronary heart disease and cerebral infarction in elderly Chinese. Lancet; 345 (8946). 1995, pp. 353-355. 
PRIMEIRA CONFERÊNCIA INTERMINISTERIAL SOBRE SAÚDE E AMBIENTE EM ÁFRICA. UNEP, OMS (2008). Gabão. 2008. Consultado em 13 de Julho de 2011. Disponível em: http://www.unep.org/health-env/ default.asp?ct=official\&sct=technicaldocs\&l=en.

Shea, K., Truckner, T., Weber, R., Peden, B. (2008). Climate change and allergic disease. J Allergy Clin Immunol September 2008;122:443-53.

Smoyer, K. (1998). A comparative analysis of heat waves and associated mortality in St. Louis, Missouri - 1980 and 1995. Int J Biometeorol 42. 1998, pp. 44-50.

Tör, K., Bartholy, T., Pongrácz, R., Kis, Z., Keller, E. \& Dunay, G. (2010). Evaluation of meteorological fators on sudden cardiovasculardeath . Journal of Forensic and Legal Medicine 17. 2010, pp. 236-242.
Wang, Y., Levi, C., Attia, J., Este, C., Sprat, N., Fisher, J. (2003). Seasonal Variation in Stroke in the Hunter Region, Australia: A 5-Year HospitalBased Study, 1995-2000. Stroke - Journal of American Heart Association, 34. 2003, pp. 1144-1150.

WORLD HEALTH ORGANIZATIONN (2009). Protecting health from climate change Connecting science, policy and people. 2009.

Ye, F., Piver, W., Ando, M. \& Portier, C. (2001). Effects of Temperature and Air Pollutants on Cardiovascular and Respiratory Diseases for Males and Females Older than 65 Years of Age in Tokyo, July and August 1980-1995. Environmental Health Perspectives, Volume 109, Number 4. April de 2001, pp. 355-359. 

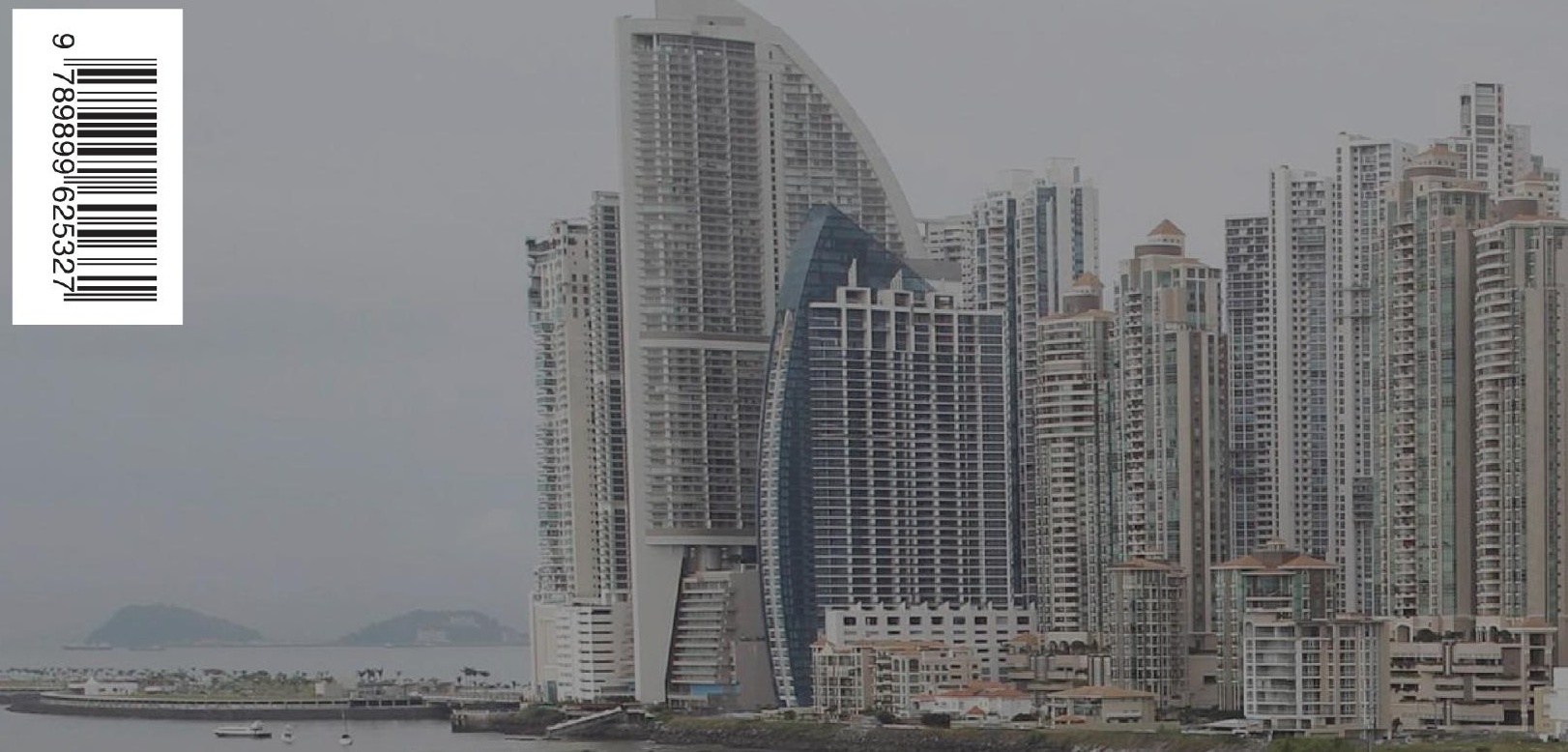

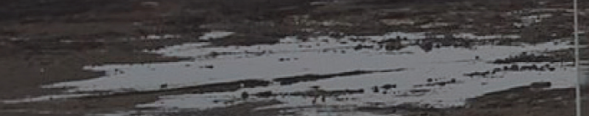

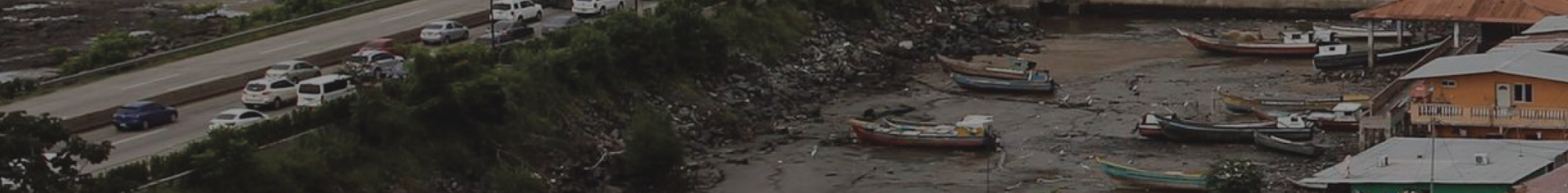

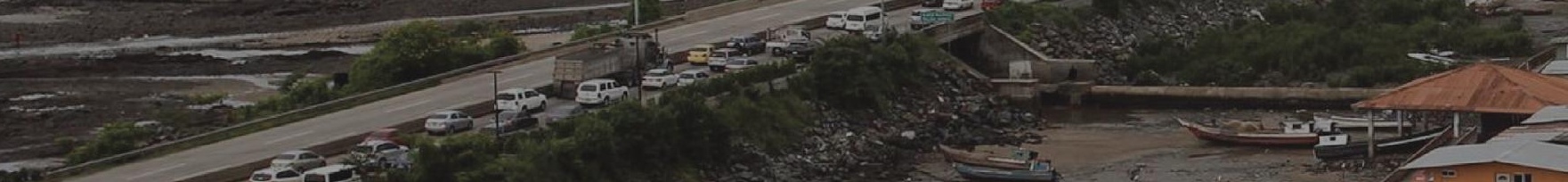
inse- $n=$ Riscos I I I

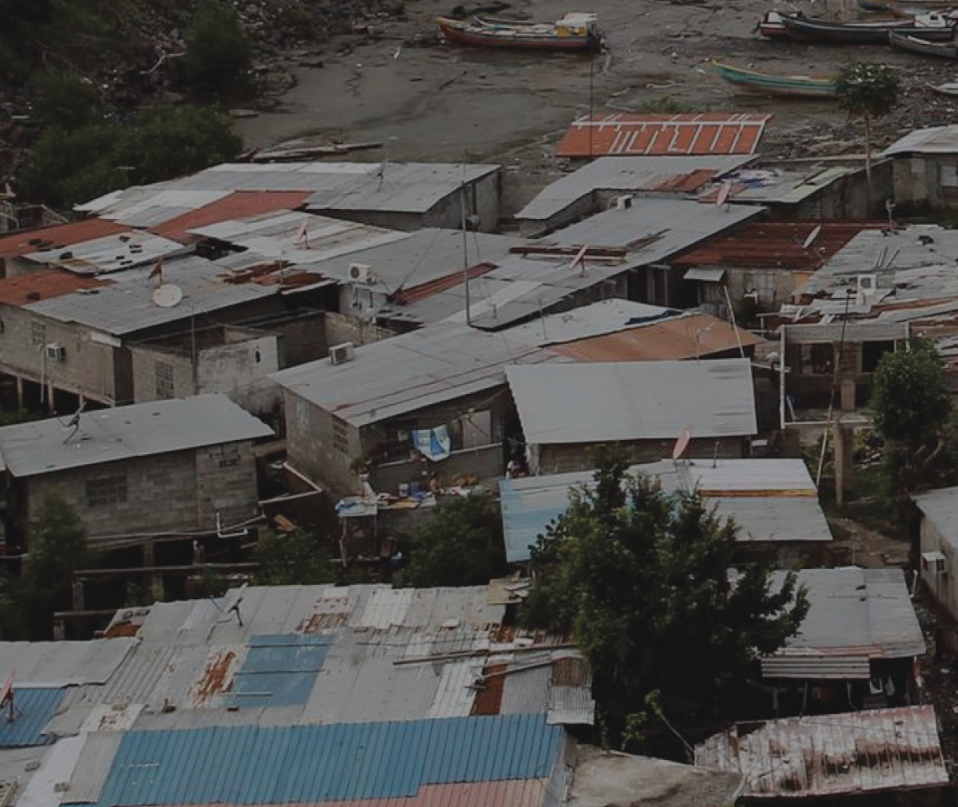

